\title{
Influence of Micro-structured Superhydrophobic Surfaces on Nucleation and Natural Convection in a Heated Pool
}

\author{
Adam Cowley \\ Daniel Maynes \\ Julie Crockett \\ Brian D. Iverson \\ Brigham Young University - Provo, bdiverson@byu.edu
}

Follow this and additional works at: https://scholarsarchive.byu.edu/facpub

Part of the Mechanical Engineering Commons

\section{Original Publication Citation}

Cowley, A., Maynes, D., Crockett, J., and Iverson, B. D., 2019, "Influence of micro-structured superhydrophobic surfaces on nucleation and natural convection in a heated pool," International Journal of Heat and Mass Transfer, Vol. 129, pp. 1095-1109. DOI: 10.1016/

j.ijheatmasstransfer.2018.10.030

\section{BYU ScholarsArchive Citation}

Cowley, Adam; Maynes, Daniel; Crockett, Julie; and Iverson, Brian D., "Influence of Micro-structured Superhydrophobic Surfaces on Nucleation and Natural Convection in a Heated Pool" (2019). Faculty Publications. 2977.

https://scholarsarchive.byu.edu/facpub/2977

This Peer-Reviewed Article is brought to you for free and open access by BYU ScholarsArchive. It has been accepted for inclusion in Faculty Publications by an authorized administrator of BYU ScholarsArchive. For more information, please contact ellen_amatangelo@byu.edu. 


\title{
Influence of Micro-structured Superhydrophobic Surfaces on Nucleation and Natural Convection in a Heated Pool
}

\author{
Adam Cowley, Daniel Maynes*, Julie Crockett, Brian D. Iverson \\ Department of Mechanical Engineering \\ Brigham Young University \\ Provo, UT 84602
}

\begin{abstract}
This work experimentally explores sub-boiling pool nucleation on micro-structured superhydrophobic surfaces. All surfaces tested were submerged in a $20 \mathrm{~mm}$ deep pool of water and heated from below to maintain a constant surface temperature, while the side walls of the pool were insulated, and the top was covered. Three thermocouples positioned in the pool obtain the average pool temperature. A heat flux sensor is placed directly beneath the surface to measure the heat flux supplied to the pool. Free convection heat transfer coefficients are obtained for the sub-boiling temperature range of $40-90^{\circ} \mathrm{C}$. Six surface types are studied: smooth hydrophilic, smooth hydrophobic, superhydrophobic with rib/cavity structures, superhydrophobic with rib/cavity structures and additional sparsely spaced ribs to close off the cavities, circular posts, and circular holes. It is found that structured superhydrophobic surfaces provide cavities for nucleation to occur. More dissolved air effervesces from the water as the surface temperature increases due to an increased level of supersaturation and convection. The nucleation leads to large air bubble formations that reduce the overall convection coefficient when compared to the smooth surfaces. For the rib/cavity structured surfaces, the bubbles form in an anisotropic manner and are aligned with the surface structure. More bubbles are observed on the superhydrophobic surfaces where the cavities are bounded. Since water's ability to dissolve air is dependent on temperature, heat and mass transfer cannot be treated independently on any of the superhydrophobic surfaces studied here.
\end{abstract}

Keywords: superhydrophobic, natural convection, heat transfer, mass transfer, nucleation

\section{Nomenclature}

a Post/hole diameter

$b_{t}$ Temperature jump length

$C_{\mathrm{A}}$ Equilibrium concentration of dissolved gas $\mathrm{A}$ in liquid

$d$ Cavity depth

$g$ Local acceleration due to gravity

$F_{c}$ Cavity fraction

$h$ Natural convection heat transfer coefficient

$\bar{h}$ Average heat transfer coefficient

$\bar{h}_{\mathrm{HPi}}$ Average heat transfer coefficient for hydrophilic smooth surface

$H^{c p}$ Henry's Law solubility constant

HPi Hydrophilic surface

HPo Hydrophobic surface

$k$ Fluid thermal conductivity for correlation

$L$ Seperation distance for correlation

$P$ Liquid pressure

$P_{A}$ Partial pressure of gas A

$P_{g}$ Total gas pressure

$\operatorname{Pr}$ Prandtl number

\footnotetext{
* Corresponding Author

Email address: maynes@byu.edu (Daniel Maynes)
}

$q^{\prime \prime}$ Heat flux

$R_{1}, R_{2}$ Mensicus radii of curvature

$R a_{L}$ Raleigh number for correlation

SHPo-R Superhydrophobic surface with rib structure

SHPo-R* Superhydrophobic surface partially patterned with rib structure

SHPo-R + Superhydrophobic surface with rib structure and sparse perendicualr ribs

SHPo-P* Superhydrophobic surface partially patterned with post structure

SHPo-H Superhydrophobic surface with hole structure

$T_{1}, T_{2}$ Temperatures for correlation

$T_{p}$ Pool temperature

$T_{s}$ Surface temperature

$\hat{T}_{c}$ Average temperature of composite interface

$\hat{T}_{s}$ Temperature of liquid/solid interface

$\bar{T}_{p}$ Temporally averaged pool temperature

$\bar{T}_{s}$ Temporally averaged surface temperature

$w$ Pitch

$w_{b}$ Sparse perpendicular rib width

$w_{c}$ Cavity width

Greek Symbols 
$\alpha$ Fluid thermal diffusivity for correlation

$\beta$ Volumetric thermal expansion coefficient of fluid for correlation

$\nu$ Fluid kinematic viscosity for correlation

$\theta$ Apparent static contact angle

$\theta_{a}$ Apparent advancing contact angle

$\theta_{r}$ Apparent receding contact angle

\section{Special Symbols}

* Indicates surfaces that were left un-textured adjacent to all edges of the pool, with the texture covering the remainder of the surface

\section{Introduction}

Superhydrophobic (SHPo) surfaces have received substantial attention due to their extreme ability to repel water. These surfaces are commonly fabricated by combining nano/micro-scale surface features with a hydrophobic coating. Due to surface tension, liquid in contact with a SHPo surface does not penetrate into the cavities and remains suspended on the tops of the features and a gas layer is trapped in between the features. This state is considered to be the Cassie-Baxter state [1] and the liquid is largely in contact with gas rather than solid (see panel (a) of Fig. 1). Sessile droplets of water can obtain very high contact angles with low hysteresis on such surfaces, leading to sliding angles of just a few degrees. SHPo surfaces have potential applications for self-cleaning surfaces, drag reduction, condensers, and lab-on-chip devices.

Superhydrophobic surfaces can lose their performance if the trapped gas layer is lost and the liquid wets the surface features (i.e. the Cassie-Baxter state is not maintained). This can occur if the pressure of the liquid above the gas cavity is sufficiently large. The meniscus curvature can be related to the pressure differential between the gas and the liquid via the Young-Laplace equation

$$
P_{g}-P=\sigma\left(\frac{1}{R_{1}}+\frac{1}{R_{2}}\right)
$$

where $P_{g}$ is the gas pressure, $P$ is the liquid pressure, $\sigma$ is the surface tension of the liquid/gas system, and $R_{1}$ and $R_{2}$ are the radii of curvature of the meniscus [2]. Note that a positive curvature is defined here to mean that the meniscus is protruding out of the cavity. When the meniscus protrudes down into the cavity far enough such that it reaches the advancing contact angle of the substrate with respect to the side of the cavity, any further increase to pressure will cause the meniscus to unpin from the cavity edge and advance down into the cavity [3]. The critical pressure required to achieve this mechanical failure is commonly referred to as the Laplace pressure.

Another failure mechanism arises from the ability of liquids to hold a certain amount of dissolved gases. This behavior is described by the classical convective-diffusive mass transport equations. The boundary condition for the concentration of gas in the liquid at the liquid/gas interface is determined from Henry's law for a dilute solution of a dissolved gas in a liquid solvent and can be expressed as

$$
C_{\mathrm{A}}=H^{c p} P_{\mathrm{A}}
$$

where $C_{\mathrm{A}}$ is the equilibrium concentration of dissolved gas A that a liquid can hold when in contact with gas $\mathrm{A}$ at partial pressure $P_{\mathrm{A}}$ and $H^{c p}$ is the Henry's Law solubility constant; which is different for each gas/liquid combination and is also dependent on temperature [4]. If the equilibrium concentration of dissolved gas is greater than the actual concentration, then the liquid is undersaturated and can accommodate more dissolved gas. When an undersaturated liquid is in contact with a SHPo surface, mass transfer can occur across the meniscus and the gas can be absorbed out of the cavities, leading to a wetted state.

Several studies have addressed the maintenance of the gas layer in the presence of mass transfer. Patankar analytically investigates a single pore with trapped gas and estimates the critical pore size at which failure will occur as a function of the saturation level of the liquid, liquid pressure, surface tension, and contact angle of the substrate [5]. His work also outlines when Henry's Law can be used accurately to predict the equilibrium concentration. He concludes that the pore size on a hydrophobic substrate (with a $110^{\circ}$ contact angle) must be sub-micron if the air is to remain trapped when submerged in degassed water at $1 \mathrm{~atm}$. Xu et al. consider a similar problem for a single trench filled with air that is submerged in water and also determine that the water must be shallower (i.e. lower liquid pressure) for larger cavity sizes to maintain the air layer for an "infinite" time [6]. Emami et al. analytically predict the time for the air layer to be absorbed in channel flow over a SHPo rib/cavity surface [7]. Kadoko et al. also analytically consider the depletion of the plastron for a rib/cavity surface, however they consider the diffusion dominated case rather than convective mass transfer [3]. Flynn and Bush examine the ability of the air layer or plastron to allow certain insects to breathe underwater [8].

These studies have been concerned primarily with maintenance or absorption of the air layer on SHPo surfaces. Notably less work has been focused on the opposite case where the liquid is supersaturated. Vakarelski et al. considered a heated SHPo sphere submerged in water [9]. Since the equilibrium concentration of air is dependent on temperature, heating water results in it becoming supersaturated with air. They found that that air layer on the SHPo sphere is not only maintained, but also grows when the water is supersaturated. Wang et al. noted that SHPo patterns on a copper substrate would exhibit bubble nucleation at sub-boiling temperatures as low as 41.5 ${ }^{\circ} \mathrm{C}$ if the water and surface were not degassed beforehand [10]. Recently, Cowley et al. explored the effects of subcritical heating on SHPo microchannels and found that large amounts of bubble nucleation could occur on the 


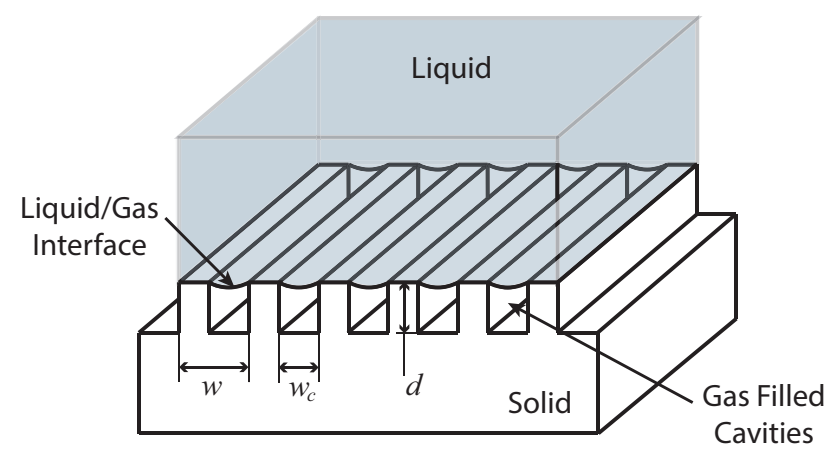

(a)

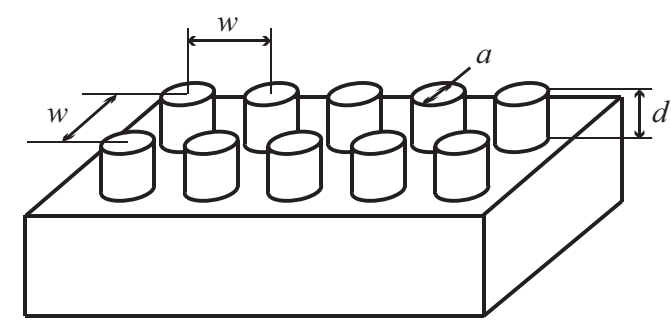

(c)

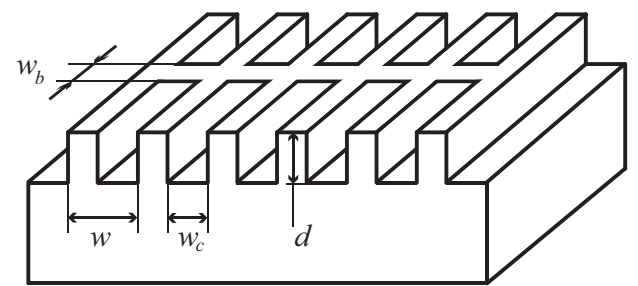

(b)

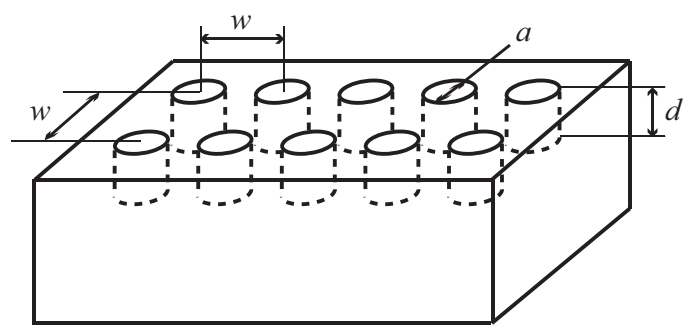

(d)

Figure 1: Panel (a): A rib/cavity structured SHPo surface. Panel (b): A rib/cavity structured SHPo surface with sparse perpendicular ribs. Panel (c): A SHPo surface structured with a square lattice of circular posts. Panel (d): A SHPo surface structured with a square lattice of circular holes. Note that the liquid is not displayed in panels (b) - (d) for clarity.

heated SHPo wall, depending on the micro-structure of the SHPo surface[11]. The presence of the bubbles in the microchannel led to degraded hydrodynamic and thermal performance. Lv et al. showed experimentally that bubbles could grow from the air trapped in circular pores when they adjusted the saturation level of water by depressurization [12]. Interestingly, they showed that a bubble's size affected if it was going to continue to grow or shrink along with the saturation level of the water. Note that the nucleation in these works is not due to boiling but mass transfer of air.

It should be noted that much work has recently been dedicated to the effect that thermally conductive SHPo surface structures can have on the thermal transport of submerged substrates [13-21]. However, these studies do not consider mass transfer and focus on how the geometry of the SHPo surface structures affects the heat transfer to the bulk fluid for diffusion dominated (i.e. Stokes flow) $[16,19]$ and convective $[13,17,18]$ microchannel flow scenarios. Essentially the trapped air in the cavities acts as an insulating layer and increases the resistance to heat transfer due to the spreading resistance caused by the surface structure geometry. The reduction to the overall convective heat transfer is dependent on the structure geometry, Peclet number, and the relative size of the surface structures to the characteristic length. It is only when the characteristic length (i.e. the hydraulic diameter for microchannel flow) is similar to the size of the SHPo surface structures (i.e. the pitch $w$, see Fig. 1) that an appreciable heat transfer reduction is observed [17, 18].

This work seeks to further investigate the nucleation behavior of air and its effect on heat transfer for structured SHPo surfaces by experimental methods. Four different types of SHPo surface structures are investigated to elucidate the role of the underlying micro-structure, which has not previously been done. The surfaces are submerged in a pool of water that is fully saturated with air and supersaturation is achieved by heating the surfaces to a range of sub-boiling temperatures $\left(40-90{ }^{\circ} \mathrm{C}\right)$ and the nucleation behavior is observed visually. The surface type and temperature both affect the level of nucleation observed. Natural convection heat transfer coefficients are obtained over the range of temperatures. The surfaces with large amounts of nucleation exhibit the lowest heat transfer coefficients due to the nucleated air bubbles acting as an insulating layer. The reduction to the heat transfer observed here is orders of magnitude more significant than the reduction predicted from considering the geometry of SHPo surface structures alone.

\section{Experimental Methods}

A custom experimental apparatus is used to heat the submerged test surfaces and record heat flux and temperature data. A cross section through the center of the test set-up is pictured in Fig. 2. An aluminum block $(63 \times 63 \times 38 \mathrm{~mm})$ is heated via four cartridge heaters that are powered by a $20 \mathrm{VAC}$ power source. A solid state 


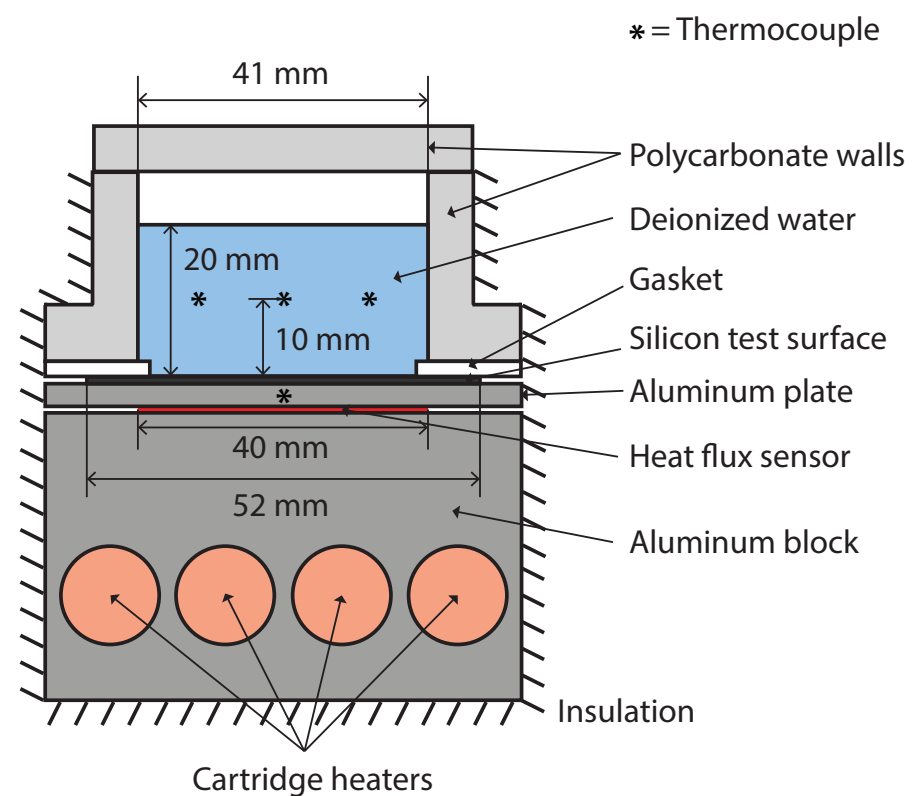

Figure 2: Cross-section of experimental apparatus.

relay in conjunction with an on/off temperature controller regulates power to the cartridge heaters in order to maintain the surface temperature at the desired set-point. Note that the cartridge heaters are positioned far enough from the top surface of the aluminum block such that a uniform surface temperature is achieved at the top of the block. A thin heat flux sensor $(40 \times 40 \times 0.3 \mathrm{~mm})$ is placed in-between the aluminum block and an aluminum plate $(63 \times 63 \times 3$ $\mathrm{mm})$ and its recorded value is taken to be the heat flux $\left(q^{\prime \prime}\right)$ through the silicon test surface. In the center of the aluminum plate a thermocouple is embedded and its recorded temperature is taken to be the surface temperature $\left(T_{s}\right)$. The test surfaces $(52 \times 52 \times 0.47 \mathrm{~mm})$ are placed in contact with the top of the aluminum plate. A thin layer of thermal compound is applied uniformly between the test surface and the aluminum plate to promote good thermal contact. Using a simple one dimensional conduction analysis, which accounts for the the aluminum plate, thermal compound, and silicon test surface, the temperature difference between the recorded surface temperature in the aluminum plate and the actual surface temperature is estimated to be nominally $0.03{ }^{\circ} \mathrm{C}$ for the highest average heat flux recorded (i.e. the worst case scenario). This is less than the differential ${ }^{1}$ resolution of the thermocouples $\left( \pm 0.1{ }^{\circ} \mathrm{C}\right)$ and thus the measured temperature is considered to be a good representation of the actual surface temperature. Around the edges of the test surface a $2 \mathrm{~mm}$ soft silicone gasket is placed between the test surface and a polycarbonate enclosure such that a water tight seal is made. The resulting enclosure above the test surface measures nominally $41 \times 41 \times 26 \mathrm{~mm}$. Due to the overhang from the gasket note that a $37 \times 39 \mathrm{~mm}$ area of the $52 \times 52$

\footnotetext{
${ }^{1}$ The absolute resolution of the thermocouples is $\pm 2.2{ }^{\circ} \mathrm{C}$.
}

$\mathrm{mm}$ test surface is actually in contact with the liquid pool (see Fig. 2). The polycarbonate enclosure is fastened to the aluminum via four machine screws that are uniformly torqued to 3 in-lbs. This results in a consistent seal with the gasket and a consistent contact pressure between the test surface and the aluminum plate. Deionized water that is fully saturated with air at room temperature (nominally $23{ }^{\circ} \mathrm{C}$ ) fills the enclosure to a depth of $20 \mathrm{~mm}$. The deionized water was stored at room temperature in a container open to the atmosphere for several days and its air content was allowed to equilibrate with the atmospheric environment. Then, just prior to experimentation, air is vigorously bubbled through the water for $30-40$ minutes to ensure that it is completely air-saturated at the start of each experiment. This process was followed in the same manner for each scenario considered. Three thermocouples are submerged in the pool so that they are $10 \mathrm{~mm}$ from the heated surface and their average is taken to be the pool temperature $\left(T_{p}\right)$. The test set up is fully insulated on all sides except for the top. Evaporation occurs at the free surface and the liquid level drops $\approx 1-2 \mathrm{~mm}$ over the course of the testing procedure. The top of the enclosure has a small hole in it such that the free surface of the pool is exposed to atmosphere and the pressure does not rise in the enclosure from evaporation. Due to the evaporation at the free surface and no insulation on the top of the enclosure, heat transfer must occur to maintain the test surface at a constant temperature and results in a measurable temperature difference between $T_{s}$ and $T_{p}$. This also results in a larger heat flux through the surface and better resolution from the heat flux sensor. Since the sides are insulated, the heat transfer is nearly one-dimensional through the test surface.

Temperature data is continually recorded from the four thermocouples at a sampling frequency of $1 \mathrm{~Hz}$ via a custom LabVIEW VI and National Instruments hardware. The data from the heat flux sensor is also recorded in LabVIEW at a frequency of $1000 \mathrm{~Hz}$, then is averaged over 1000 samples to match the sampling frequency of the thermocouples. For each test, the surface temperature set-point is initially set to $40{ }^{\circ} \mathrm{C}$. It is then left at $40{ }^{\circ} \mathrm{C}$ for nominally 60 minutes such that a suitable range of steady-state data is available for analysis. Then, the surface temperature is ramped up to $50{ }^{\circ} \mathrm{C}$ and is held there for nominally 50 minutes. This process is continued in $10{ }^{\circ} \mathrm{C}$ increments up to a value of $90^{\circ} \mathrm{C}$ with a $45-70$ minute rest time at each set-point value. Prior to increasing the surface temperature, the top of the enclosure is removed and imaged from above with a DSLR camera to visualize the quasi-steady nucleation behavior at the given surface temperature. Due to the on/off behavior of the temperature controller, there are small cycles of heating and cooling within each set-point time period that cause peaks and troughs in the heat flux data. A peak-to-peak range of steady-state data that spans several cycles is selected for temporal averaging at each corresponding set point. A graphical example of this process is shown for a 
smooth silicon test surface in Fig. 3 for the surface temperature set-point of $60{ }^{\circ} \mathrm{C}$. Note that the large dips in $T_{p}$ correspond to when the lid is removed for imaging.

Six different types of surfaces were explored in this study: smooth hydrophilic ( $\mathrm{HPi})$, smooth hydrophobic (HPo), superhydrophobic with a rib/cavity structure (SHPoR) (see panel (a) of Fig. 1), superhydrophobic with a rib/cavity structure and additional sparse perpendicular ribs (SHPo-R+) (see panel (b) of Fig. 1), superhydrophobic with a square lattice of circular posts (SHPo-P) (see panel (c) of Fig. 1), and superhydrophobic with a square lattice of circular holes (SHPo-H) (see panel (d) of Fig. 1). Note the naming convention for the surface types defined in parenthetical text above is used for the remainder of the text. The HPi surface is simply a clean silicon wafer. The HPo surface is fabricated by first coating a silicon wafer with $100 \mathrm{~nm}$ of chromium to promote adhesion of a subsequently spun on thin PTFE coating. The SHPo surfaces are fabricated using standard photolithography processes with silicon as the substrate. The desired surface features are achieved by etching the cavities to a nominal depth $(d)$ of $20 \mu \mathrm{m}$. After etching, the structured surfaces are coated with chromium and PTFE to render them superhydrophobic. All surface types are then diced to the desired dimensions $(52 \times 52 \mathrm{~mm})$ and coated with a second PTFE layer. The sparse perpendicular ribs on the SHPo-R+ surfaces are spaced more than an order of magnitude further apart than the primary rib/cavity structures. For the SHPo-R + surfaces, several different combinations of pitch $(w)$ and cavity width $\left(w_{c}\right)$ are explored. A useful metric for comparing the different surface types is the cavity fraction $\left(F_{c}\right)$, which is defined as the ratio of the projected liquid/gas interface to the overall projected interface. For the rib/cavity structured surfaces the cavity fraction is simply $F_{c}=w_{c} / w$. For the post surfaces $F_{c}=1-\pi(a / 2 w)^{2}$ and for the hole surfaces $F_{c}=\pi(a / 2 w)^{2}$ where $a$ is the diameter of the post/hole. Table 1 contains the relevant dimensions for all the surfaces tested. Some surfaces are marked with a "* " which signifies that the micro-structure pattern only spans a $32 \times 32 \mathrm{~mm}$ square patch in the center of the test surface. The reason for patterning the selected surfaces as such will be discussed later in 3.1. Note that for the SHPo-R+ surfaces the spacing between the sparse perpendicular ribs is consistently 2.5 $\mathrm{mm}$ and the width of the sparse ribs $\left(w_{b}\right)$ is given for each of the surfaces tested in Table 1. The micro-structure dimensions are obtained with a 3D profilometer and have an uncertainty of nominally $\pm 0.5 \mu \mathrm{m}$.

Also contained in Table 1 are the static $(\theta)$, advancing $\left(\theta_{a}\right)$, and receding $\left(\theta_{r}\right)$ contact angles for droplets on the surfaces. Droplets exhibit different apparent contact angles with the rib/cavity structured surfaces depending on the orientation of the rib micro-structure due to the anisotropy of the structure. As such, contact angles are reported for droplets both in the transverse (perpendicular) and longitudinal (parallel) directions on the rib/cavity structured surfaces. All contact angle measurements have an uncertainty of $\pm 4^{\circ}$. Note that the SHPo-H surface may not technically be considered superhydrophobic since its static contact is less then nominally $145^{\circ}$ [22], however, the micro-holes do trap air and act as nucleation sites as will be discussed in the following section.

\section{Results and Discussion}

\subsection{Visualization of Nucleation Behavior}

Images of the HPi surface (viewed from a top-down perspective) after each of the six surface temperature setpoint time periods are shown in Fig. 4 as a baseline for comparison with the other surface types. Note that in all of the visualization images the test surface is pictured in the center and is bordered by the silicone gasket. On the periphery of the images the vertical side walls of the polycarbonate enclosure are visible. Along the bottom edge of the images, the polycarbonate side wall partially obscures the gasket due to a slight inclination of the camera (see panels (a) and (b)). As described in Sec. 2, nominally a $37 \times 39 \mathrm{~mm}$ area of the $52 \times 52 \mathrm{~mm}$ test surface is actually in contact with the liquid pool and is visible. It can be seen that very little nucleation occurs on the HPi surface itself since it is smooth and has few potential nucleation sites. Additionally, when water initially comes into contact with the HPi surface it can penetrate and completely wet any potential nucleation sites and render them inactive [23]. Some air bubbles do nucleate on the side walls and at the intersection of the gasket and test surface.

Images for the smooth HPo surface are shown in Fig. 5. It can be seen that several active nucleation sites exist on this surface away from the side walls. These sites are active because the hydrophobic coating prevents the water from wetting the small defects on the surface, due to surface tension, and air remains trapped inside them [23]. It can be seen that the bubbles grow in size between each temperature set point (see panels (a) - (e)). As the temperature increases, the equilibrium concentration of air that water can hold decreases and the water becomes further supersaturated thus leading to increased mass transport of air from the bulk water to the air bubbles trapped at the nucleation sites. At the $90{ }^{\circ} \mathrm{C}$ surface temperature set-point some of the bubbles grow large enough to merge (see panel (f)).

Images are shown for the SHPo-R surface $(w=40.0$ $\left.\mu \mathrm{m}, F_{c}=0.78\right)$ for three set-point surface temperatures $\left(40,60\right.$, and $\left.80^{\circ} \mathrm{C}\right)$ in Fig 6 . The ribs are aligned vertically and note that only two large bubbles along the sides are present, and they are aligned with the micro-rib orientation. This behavior is unexpected but occurs for the following reason. Due to the concentration gradient from heating, air is transported to all of the cavities on the surface. However, it is channeled via a thin air bubble along the top of the edge (see panel (b)), which is in contact with all the cavities, to the two side bubbles (see panel (c)) such that bubbles do not grow in the center of the 

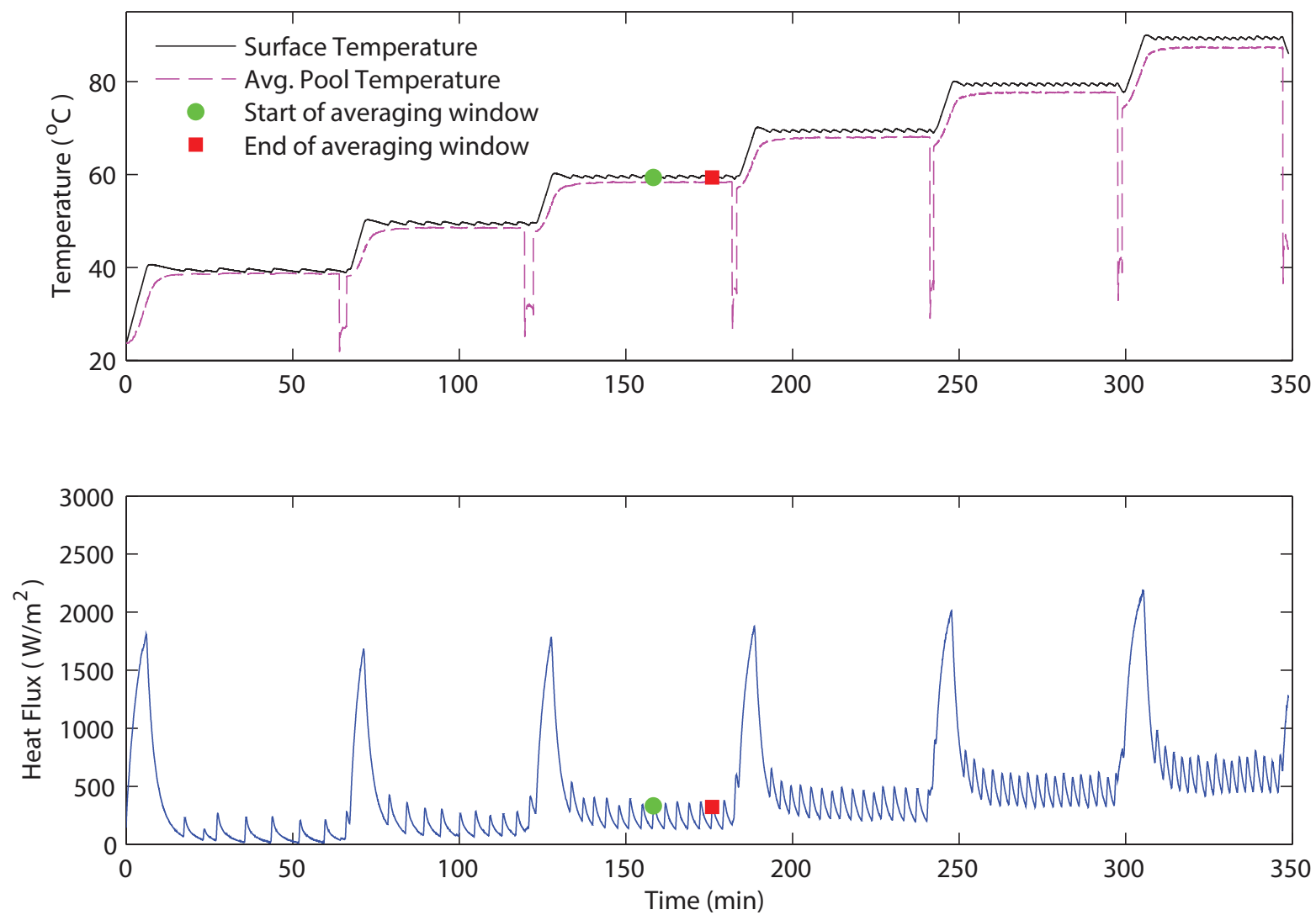

Figure 3: Plots of surface temperature $\left(T_{s}\right)$ and average pool temperature $\left(T_{p}\right)$ vs. time (top) and heat flux $\left(q^{\prime \prime}\right)$ vs. time (bottom). Plots are for a smooth silicon surface test surface and demonstrate the period over which the temporal averaging takes place for the $60^{\circ} \mathrm{C}$ surface temperature set-point. This process is repeated for each surface temperature considered.

Table 1: Outline of the surface types explored and their respective dimensions and contact angles. Static $(\theta)$, advancing $\left(\theta_{a}\right)$, and receding $\left(\theta_{r}\right)$ contact angles are presented for each surface type. Contact angles are presented for both the transverse and longitudinal orientations for the anisotropic rib/cavity structured surfaces. The surfaces marked with a " * " have a micro-structure pattern that only spans a $32 \times 32$ $\mathrm{mm}$ square patch in the center of the test surface.

\begin{tabular}{|c|c|c|c|c|c|c|c|c|c|c|c|c|}
\hline \multirow[t]{3}{*}{ Surface } & \multicolumn{6}{|c|}{ Dimensions } & \multicolumn{6}{|c|}{ Contact angles } \\
\hline & \multirow[t]{2}{*}{$w(\mu \mathrm{m})$} & \multirow[t]{2}{*}{$F_{c}$} & \multirow[t]{2}{*}{$w_{c}(\mu \mathrm{m})$} & \multirow[t]{2}{*}{$a(\mu \mathrm{m})$} & \multirow[t]{2}{*}{$d(\mu \mathrm{m})$} & \multirow[t]{2}{*}{$w_{b}(\mu \mathrm{m})$} & \multicolumn{3}{|c|}{$\begin{array}{l}\text { Transverse orientation } \\
\text { or Isotropic surface }\end{array}$} & \multicolumn{3}{|c|}{$\begin{array}{l}\text { Longitudinal } \\
\text { orientation }\end{array}$} \\
\hline & & & & & & & $\theta\left({ }^{\circ}\right)$ & $\theta_{a}\left(^{\circ}\right)$ & $\theta_{r}\left(^{\circ}\right)$ & $\theta\left({ }^{\circ}\right)$ & $\theta_{a}\left(^{\circ}\right)$ & $\theta_{r}\left(^{\circ}\right)$ \\
\hline $\mathrm{HPi}$ & - & - & - & - & - & - & 69 & - & - & - & - & - \\
\hline $\mathrm{HPo}$ & - & - & - & - & - & - & 117 & 126 & 114 & - & - & - \\
\hline SHPo-R & 40.0 & 0.78 & 31.2 & - & 21.1 & - & 153 & 163 & 139 & 147 & 146 & 141 \\
\hline $\mathrm{SHP}_{\mathrm{O}-\mathrm{R}^{*}}$ & 39.9 & 0.79 & 31.6 & - & 20.0 & - & 152 & 161 & 143 & 146 & 148 & 141 \\
\hline $\mathrm{SHPo}-\mathrm{R}+$ & 40.0 & 0.78 & 31.1 & - & 20.0 & 8.9 & 148 & 162 & 133 & 144 & 147 & 130 \\
\hline $\mathrm{SHPo}-\mathrm{R}+$ & 40.1 & 0.55 & 21.9 & - & 23.9 & 7.2 & 152 & 160 & 133 & 138 & 140 & 130 \\
\hline $\mathrm{SHPo}-\mathrm{R}+$ & 24.0 & 0.89 & 21.4 & - & 20.9 & 6.2 & 154 & 157 & 142 & 154 & 154 & 147 \\
\hline SHPo-H & 24.0 & 0.51 & - & 19.2 & 21.6 & - & 132 & 140 & 118 & - & - & - \\
\hline SHPo-P* & 23.6 & 0.60 & - & 16.8 & 21.1 & - & 150 & 158 & 127 & - & - & - \\
\hline
\end{tabular}




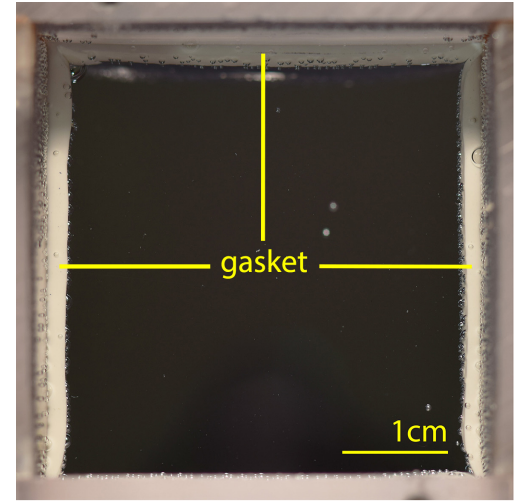

(a) $40^{\circ} \mathrm{C}$

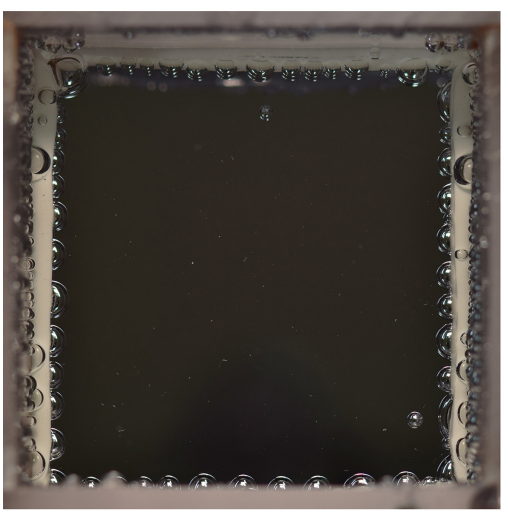

(d) $70^{\circ} \mathrm{C}$

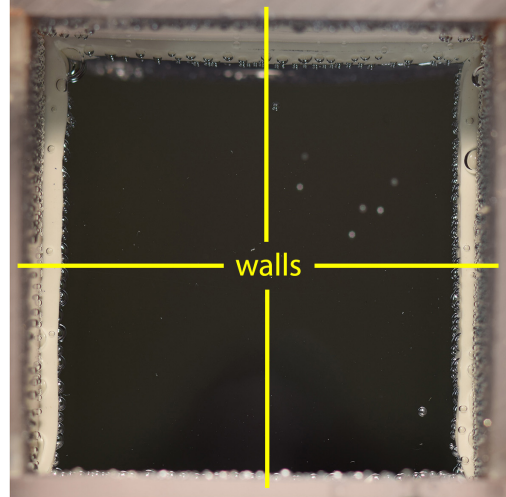

(b) $50^{\circ} \mathrm{C}$

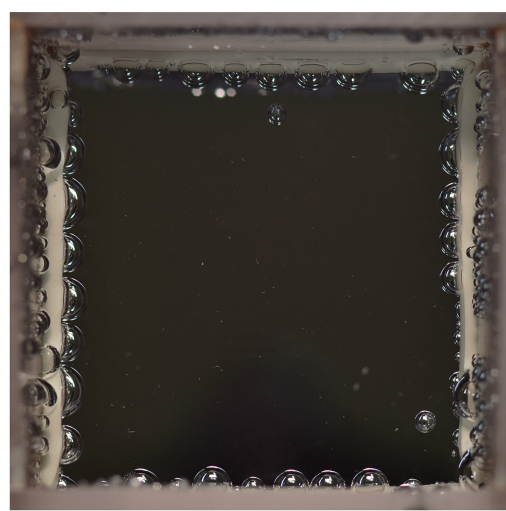

(e) $80^{\circ} \mathrm{C}$

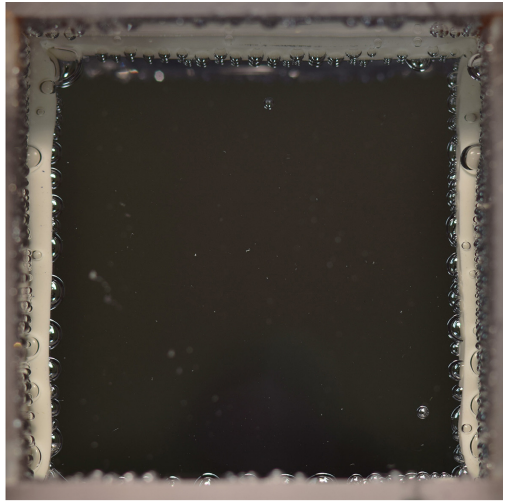

(c) $60^{\circ} \mathrm{C}$

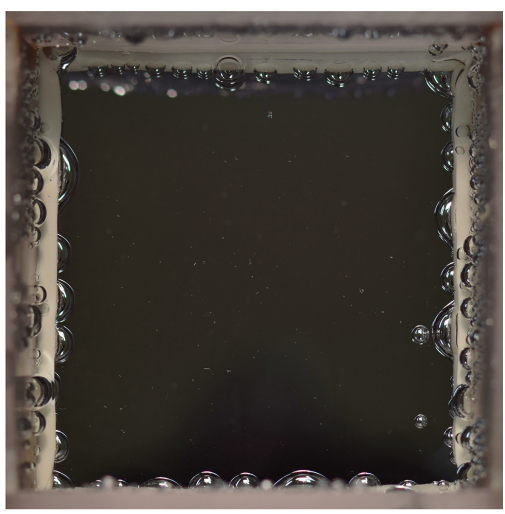

(f) $90^{\circ} \mathrm{C}$

Figure 4: Top-view of nucleation behavior on the HPi surface at the six surface temperature set-points. The scale bar included in panel (a) is the same for all panels. 


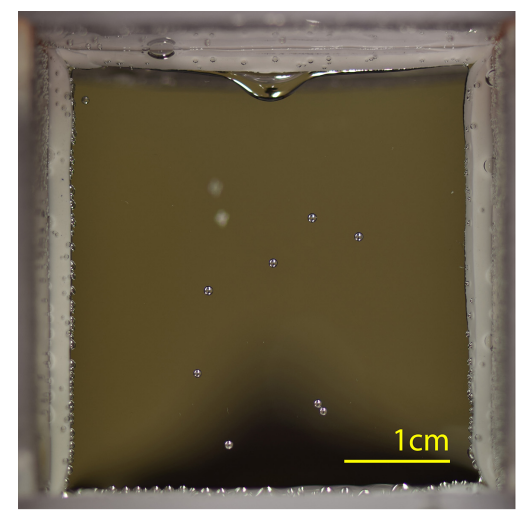

(a) $40^{\circ} \mathrm{C}$

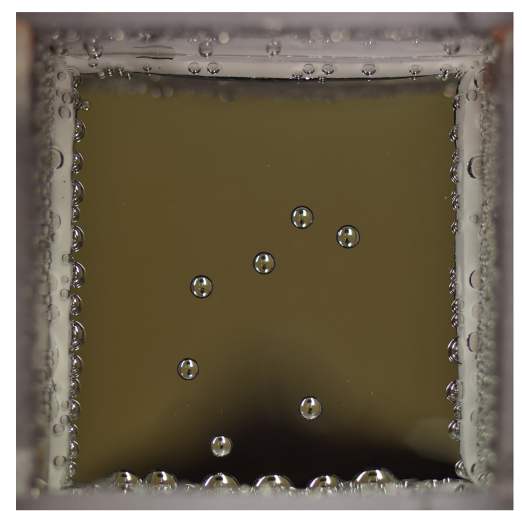

(d) $70^{\circ} \mathrm{C}$

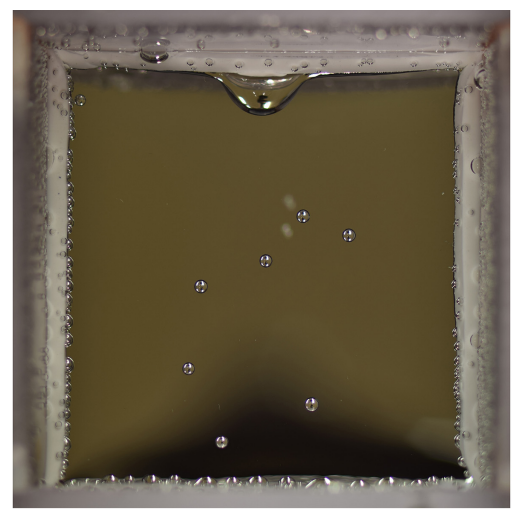

(b) $50^{\circ} \mathrm{C}$

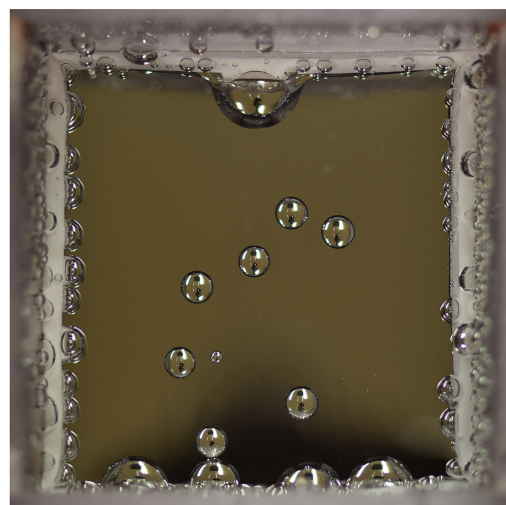

(e) $80^{\circ} \mathrm{C}$

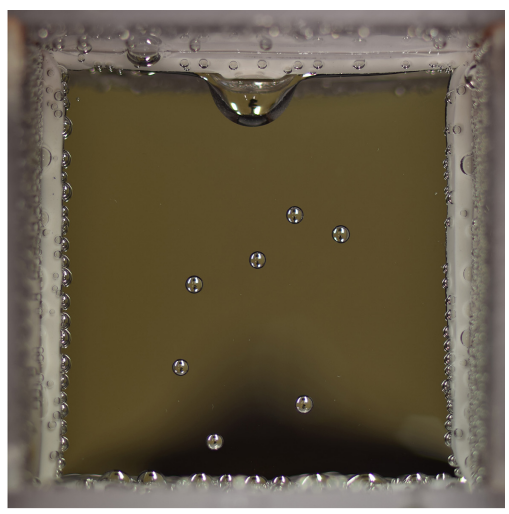

(c) $60^{\circ} \mathrm{C}$

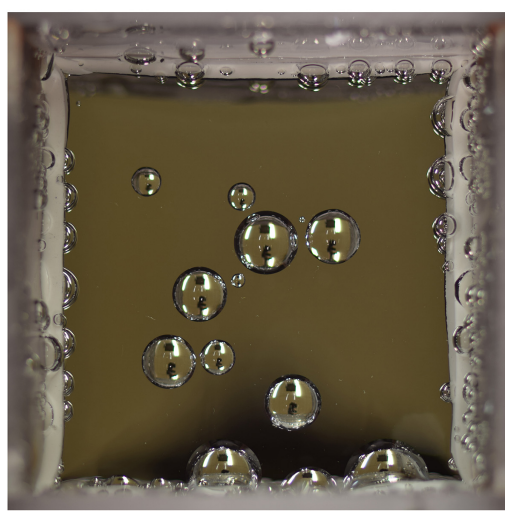

(f) $90^{\circ} \mathrm{C}$

Figure 5: Top-view of nucleation behavior on the HPo surface at the six surface temperature set-points. 
surface. This is consistent with the findings of Huynh et al. which show that a captive bubble on a SHPo surface can grow via injection of air elsewhere on the surface into the plastron [24]. To further illustrate this phenomenon, visualization images for the SHPo-R* surface with the same micro-structure $\left(w=39.9 \mu \mathrm{m}, F_{c}=0.79\right)$ are shown in Fig. 7. Recall for this surface that only a $32 \times 32 \mathrm{~mm}$ square in the center of the test section is patterned with the micro-structure such that the cavities are isolated from interference with the side walls and sealing gasket. Note the vast differences in the nucleation behavior when the cavities are isolated from the bubbles on the edges. The air can no longer move freely from the inter-rib cavities toward the thin air bubble along the top, since for this surface the top air bubble is not initially in contact with any of the inter-rib cavities (see panel (a)). Thus, many anisotropic bubbles form that are aligned with the microstructure, but that are bounded. As the bubbles continue to grow with increasing $T_{s}$, they merge with neighboring bubbles and become wider and less elongated to minimize surface energy. Also note that only one bubble touches any given cavity, i.e. all the cavities a bubble is in contact with, will not have another bubble in contact with them. This occurs because as additional air is transported to a cavity, it will flow through the cavity and add to the large bubble already in contact with the cavity in order to minimize surface energy. Eventually, if enough air is transported, the bubbles may detach due to buoyancy forces (compare panels (e) and (f)).

The concept of isolating the air cavities from one another is further explored by the addition of sparse ribs that are spaced $2.5 \mathrm{~mm}$ apart and aligned perpendicular to the main rib micro-structure. In Fig. 8 visualization images for the SHPo-R+ surface with $w=40.0 \mu \mathrm{m}$ and $F_{c}=0.78$ are shown. The nucleation behavior is drastically changed when compared to the SHPo-R and SHPo$\mathrm{R}^{*}$ surfaces. The additional ribs create many more closed off air cavities and as such many bubbles can nucleate independently and more completely cover the surface. The bubbles eventually merge and become larger once enough mass transport has occurred. Note that the larger bubbles are less anisotropic and have circular shape on the SHPo$\mathrm{R}+$ surface rather than an elongated one as seen on the SHPo-R* surface (compare panel (f) of Fig. 8 and (e) of Fig. 7).

Two other SHPo-R + surfaces are tested that have different pitch and cavity fraction values to explore the influence of the micro-structure dimensions. In Fig. 9 visualization images at three surface temperature set-points (50, 70, and $90^{\circ} \mathrm{C}$ ) are shown for the SHPo-R+ surface with $w=40.1 \mu \mathrm{m}$ and $F_{c}=0.55$. The main difference between the 0.78 and 0.55 cavity fraction SHPo-R+ surfaces is the size of the large bubbles at the final temperature of $90{ }^{\circ} \mathrm{C}$; the largest bubbles on the $F_{c}=0.55$ surface have base diameter that is about half the size as the largest bubbles on the $F_{c}=0.78$ surface (compare panel (f) of Fig. 8 with panel (c) of Fig. 9). Otherwise, the overall nu- cleation behavior and bubble formations are very similar. In Fig. 10 visualization images at the same three surface temperature set-points $\left(50,70\right.$, and $90^{\circ} \mathrm{C}$ ) are shown for the SHPo-R + surface with $w=24.0 \mu \mathrm{m}$ and $F_{c}=0.89$. It can be seen in panel (a) that the initial nucleation bubbles at the beginning of the temperature range are narrower than the prior two SHPo-R+ surfaces discussed (compare panel (b) of Fig. 8, panel (a) of Fig. 9, and panel (a) of Fig. 10). Also note that on the $w=24.0 \mu \mathrm{m}, F_{c}=0.89$ SHPo-R + surface that the bubbles at the final temperature are slightly larger than those on the $w=40.0 \mu \mathrm{m}$, $F_{c}=0.78$ SHPo-R + surface (see panel (c) of Fig. 10). From these observations it can be seen that both the pitch and the cavity fraction affect bubble nucleation. It appears that pitch is related to the bubble width at lower temperatures, while cavity fraction is related to the largest bubble size possible once a majority of the smaller bubbles have merged into large ones. Essentially, the pitch indicates the number of separated air cavities per unit length on the surface, i.e. smaller pitch means more nucleation sites per unit length. Thus, more bubbles can initially form over the same transverse distance, resulting in narrower bubbles on the $24 \mu \mathrm{m}$ pitch SHPo-R+ surface relative to the two $w=40 \mu \mathrm{m}$ SHPo-R + surfaces when the sparse rib spacing in the other direction is maintained constant. Once the smaller bubbles have merged into larger ones that span many cavities, the cavity fraction seemingly becomes the dominant factor in bubble size. Since the large air bubbles at the final surface temperatures are much greater than the capillary length, a balance of surface energy forces, buoyancy forces, and amount of mass transfer will dictate the bubble size. As such, the cavity fraction may not be the only factor that determines the size of the large bubbles. Interestingly, the cavity width $\left(w_{c}\right)$ is nominally the same for both the $w=24.0 \mu \mathrm{m}, F_{c}=0.89$ and $w=40.1 \mu \mathrm{m}$, $F_{c}=0.55$ SHPo-R + surfaces, yet the nucleation behavior is different as discussed above. Since the spacing of the sparse ribs that are perpendicular to the predominant rib micro-structure was not varied and maintained at 2.5 $\mathrm{mm}$, the longitudinal span of the small/mid-size bubbles for all three SHPo-R + surfaces is similar and appears to be very dependent on the sparse rib spacing (see panel (d) of Fig. 8, panel (b) of Fig. 9, and panel (b) of Fig. 10). It is predicted that changing the spacing of the sparse ribs will also change the longitudinal span of the bubbles (in a similar manner to how the pitch affected the transverse span). However, once the sparse rib spacing becomes large enough, it is predicted that the bubbles will adjust their own longitudinal span to minimize surface energy in a similar manner as the SHPo-R* case (see panel (c) of Fig. 7).

The air cavities are further isolated from each other on the $\mathrm{SHPo-H}$ surface that is patterned with a square lattice of circular holes. Visualization images are shown for the SHPo-H surface $\left(w=24.0 \mu \mathrm{m}, F_{c}=0.51\right)$ in Fig. 11 for the six surface temperature set-points. Each hole can serve as an active nucleation site and is isolated by the substrate from any neighboring site. Also, the pitch is the 


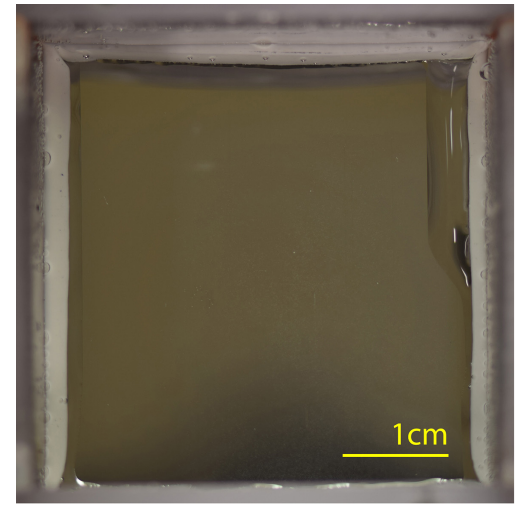

(a) $40^{\circ} \mathrm{C}$

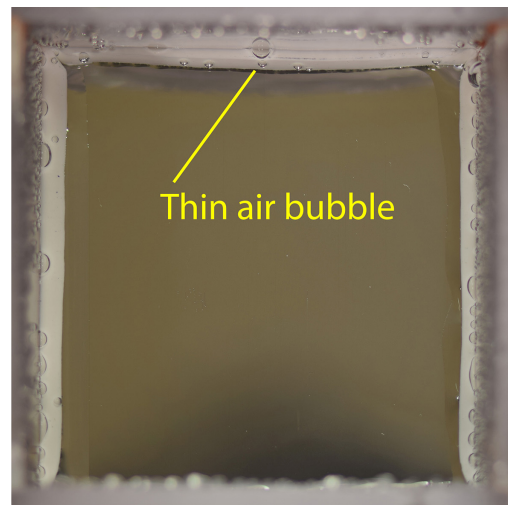

(b) $60^{\circ} \mathrm{C}$

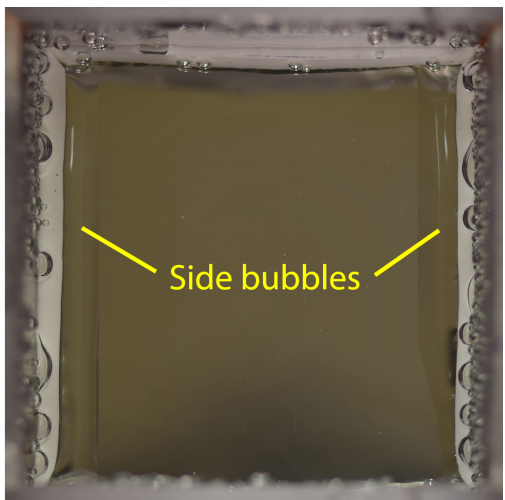

(c) $80^{\circ} \mathrm{C}$

Figure 6: Top-view of nucleation behavior on the SHPo-R surface $\left(w=40.0 \mu \mathrm{m}, F_{c}=0.78\right)$ at three of the six surface temperature set-points $\left(40,60\right.$, and $\left.80^{\circ} \mathrm{C}\right)$. The ribs are aligned vertically in the images.

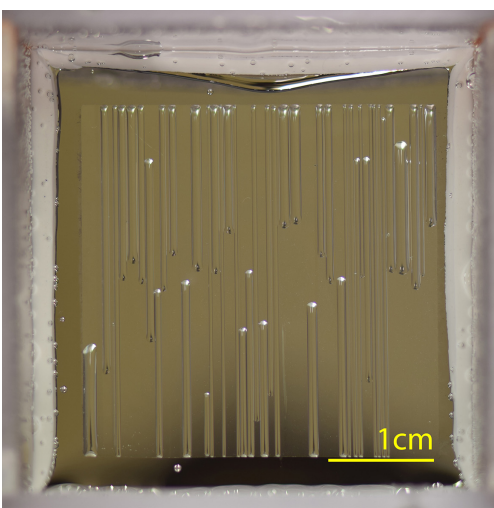

(a) $40^{\circ} \mathrm{C}$

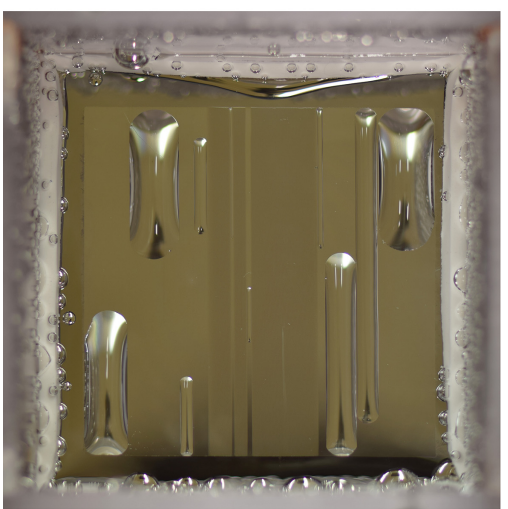

(d) $70^{\circ} \mathrm{C}$

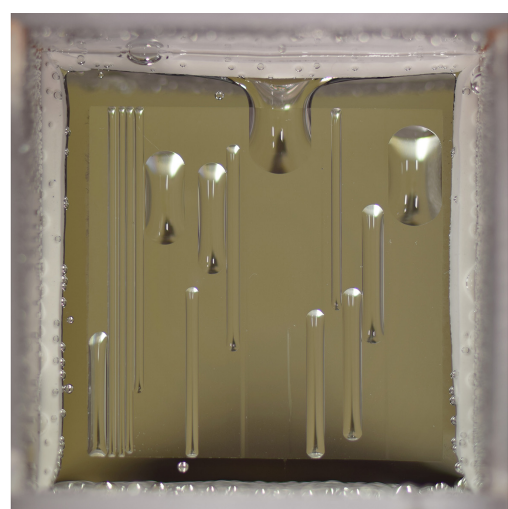

(b) $50^{\circ} \mathrm{C}$

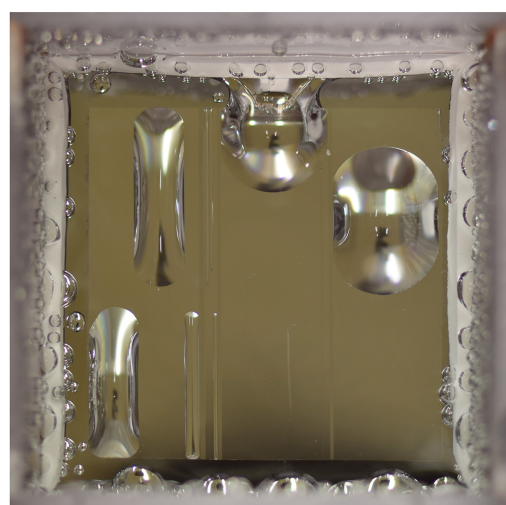

(e) $80^{\circ} \mathrm{C}$

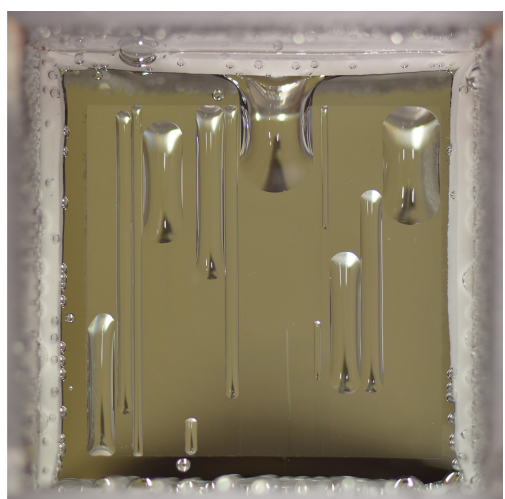

(c) $60^{\circ} \mathrm{C}$

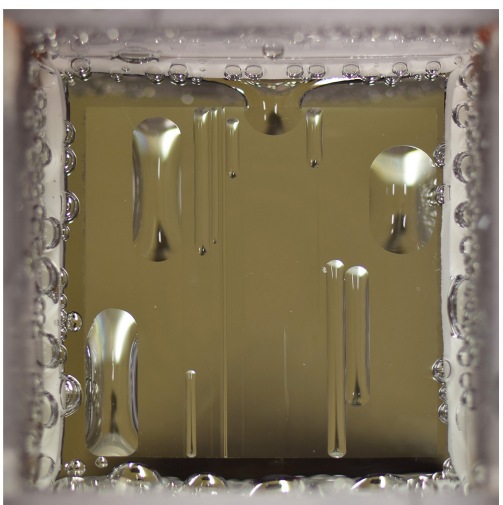

(f) $90^{\circ} \mathrm{C}$

Figure 7: Top-view of nucleation behavior on the SHPo-R* surface $\left(w=39.9 \mu \mathrm{m}, F_{c}=0.79\right)$ at the six surface temperature set-points. The ribs are aligned vertically in the images. 


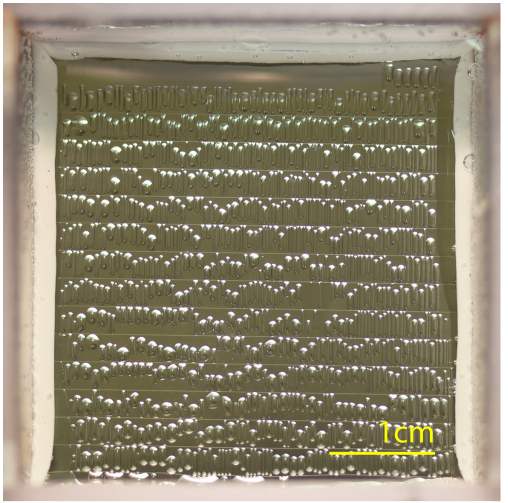

(a) $40^{\circ} \mathrm{C}$

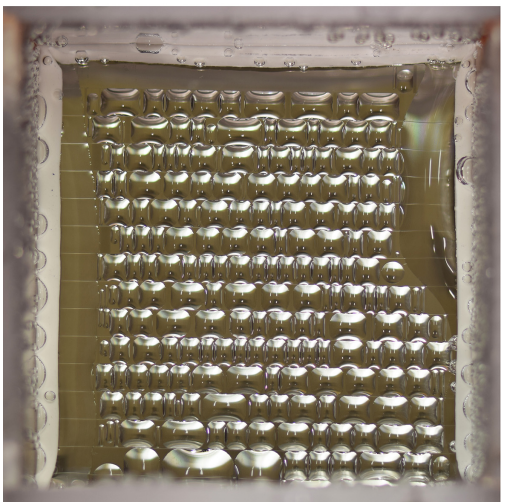

(d) $70^{\circ} \mathrm{C}$

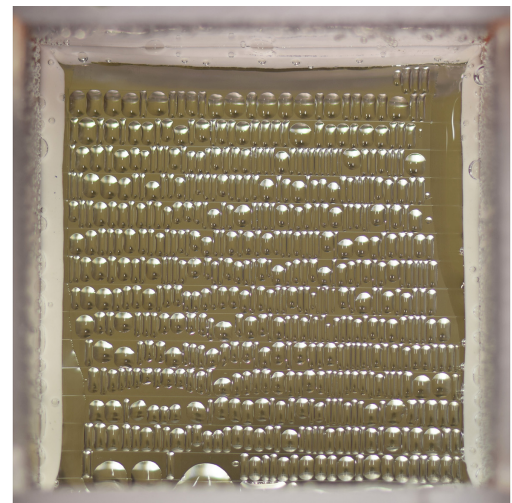

(b) $50^{\circ} \mathrm{C}$

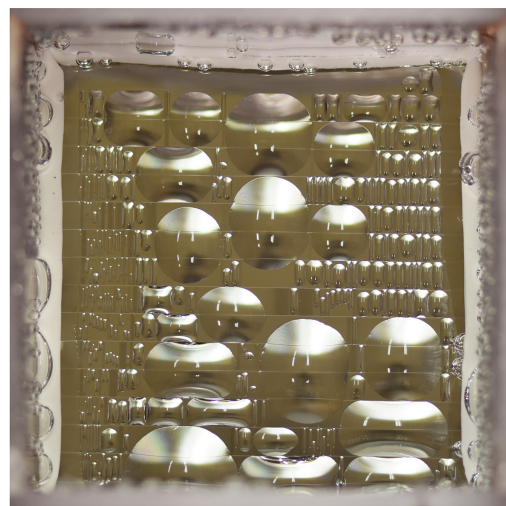

(e) $80^{\circ} \mathrm{C}$

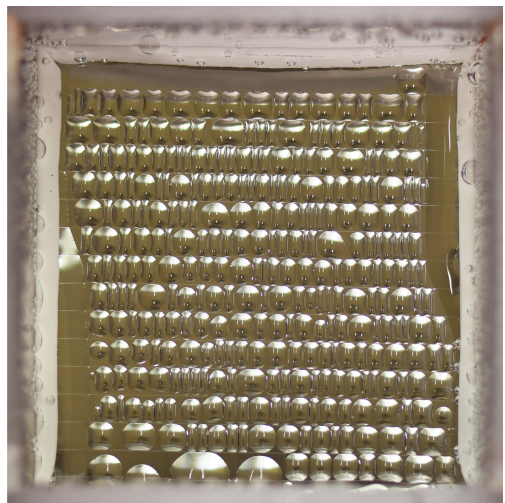

(c) $60^{\circ} \mathrm{C}$

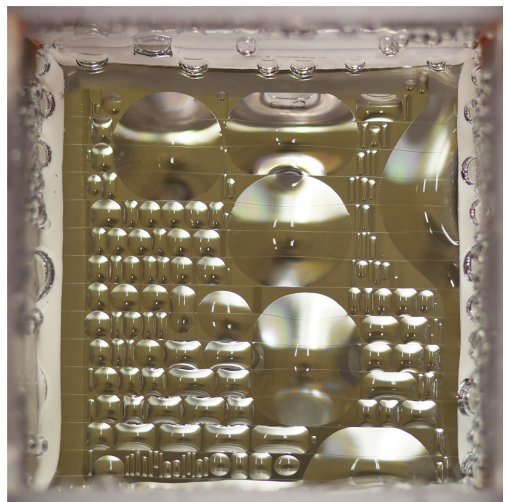

(f) $90^{\circ} \mathrm{C}$

Figure 8: Top-view of nucleation behavior on the SHPo-R+ surface $\left(w=40.0 \mu \mathrm{m}, F_{c}=0.78\right)$ at the six surface temperature set-points. The predominant rib micro-structure is vertically aligned in the images.

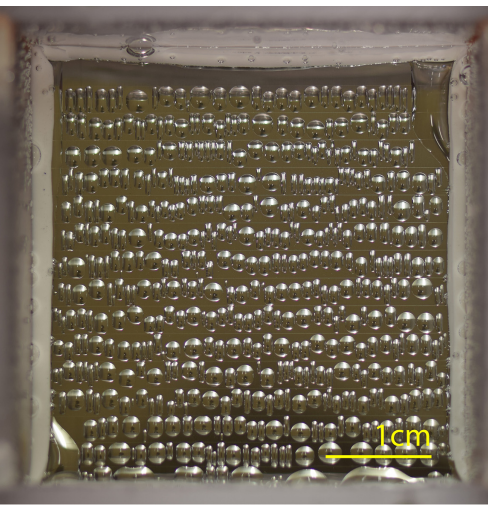

(a) $50^{\circ} \mathrm{C}$

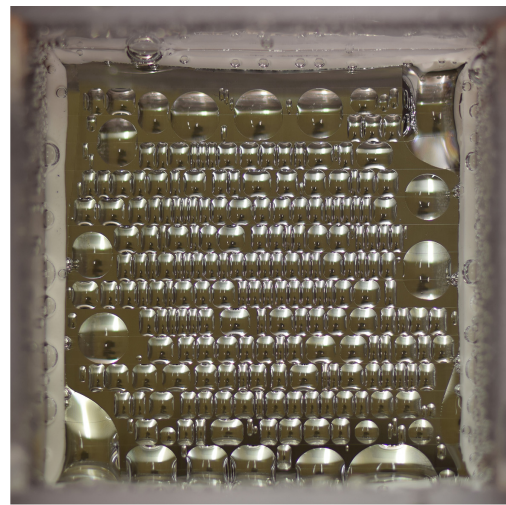

(b) $70^{\circ} \mathrm{C}$

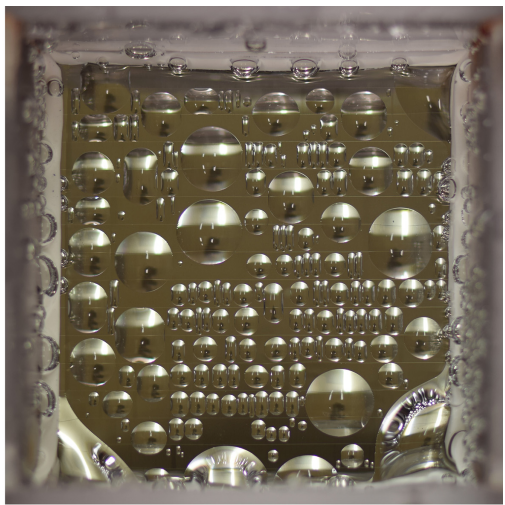

(c) $90^{\circ} \mathrm{C}$

Figure 9: Top-view of nucleation behavior on the SHPo-R+ surface $\left(w=40.1 \mu \mathrm{m}, F_{c}=0.55\right)$ at three of the six surface temperature set-points $\left(50,70\right.$, and $\left.90^{\circ} \mathrm{C}\right)$. The predominant rib micro-structure is vertically aligned in the images. 


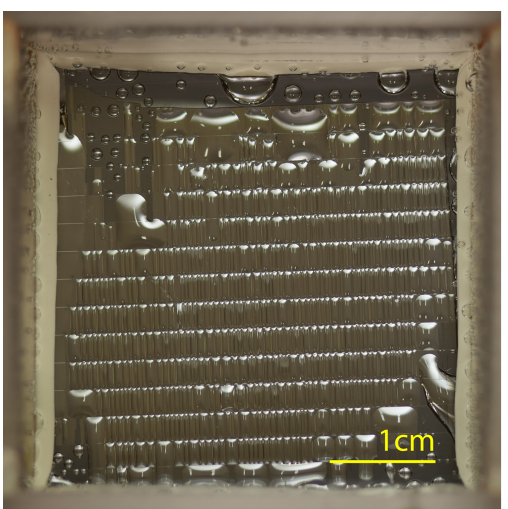

(a) $50^{\circ} \mathrm{C}$

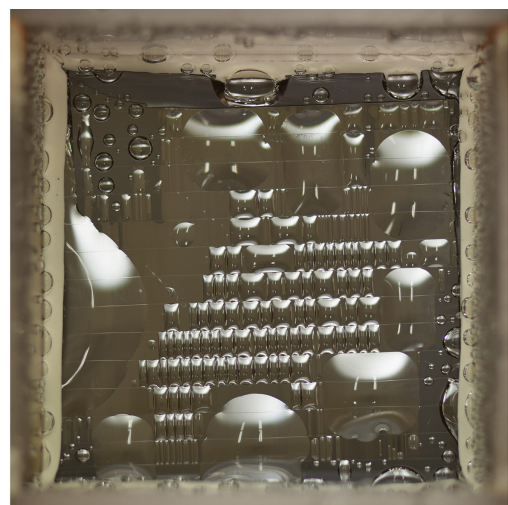

(b) $70^{\circ} \mathrm{C}$

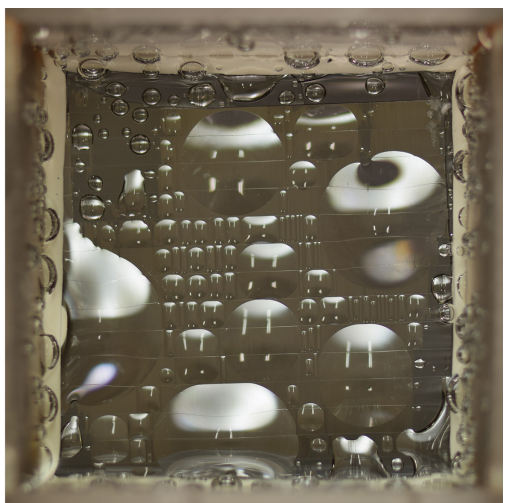

(c) $90^{\circ} \mathrm{C}$

Figure 10: Top-view of nucleation behavior on the SHPo-R+ surface $\left(w=24.0 \mu \mathrm{m}, F_{c}=0.89\right)$ at three of the six surface temperature set-points $\left(50,70\right.$, and $\left.90^{\circ} \mathrm{C}\right)$. The predominant rib micro-structure is vertically aligned in the images.

same in both primary directions for the SHPo-H surface, opposed to the rib/cavity structured surfaces. As such, the nucleation is much more isotropic for the hole patterned surface relative to the rib patterned surfaces.

The inverse case is also explored with a post structured surface. Images for the SHPo-P* ${ }^{*}$ surface $(w=23.6$ $\left.\mu \mathrm{m}, F_{c}=0.60\right)$ are shown in Fig. 12 for each of the six temperature set-points. Note that this surface is only patterned over a $32 \times 32 \mathrm{~mm}$ square in the center to isolate the air cavities from the edges. It can be seen that only one bubble nucleates on the post surface since all of the air cavities are connected. As mass is transfered via the menisci, it redirects via the air network between the post structures to the one bubble. The bubble maintains a relatively consistent base size and further mass transfer leads to bubble pinch-off and departure due to buoyancy (compare between panels (b) and (c), and between (d) and (e)). However, after the $80{ }^{\circ} \mathrm{C}$ set-point a bubble from the edge (see top left of panel (e)) encroaches on the patterned center. Subsequently, air is drawn from the main bubble via the air network in the micro-structure lattice towards the side bubble and the main bubble actually decreases in size during the $90{ }^{\circ} \mathrm{C}$ set-point condition (compare panels (e) and $(\mathrm{f}))$.

For completeness, a test using water that is degassed using a vacuum chamber is performed on the SHPo-R+ surface $\left(w=40.0 \mu \mathrm{m}, F_{c}=0.78\right)$. Visualization images are shown in Fig. 13 for this series of tests. Initially, the micro-scale cavities wet since the degassed water absorbs the air that was in the cavities. At the conclusion of the $40{ }^{\circ} \mathrm{C}$ set-point condition no nucleation is observed (see panel (a)). However, after the $50{ }^{\circ} \mathrm{C}$ set-point condition some nucleation does start to occur from isolated cavities. These cavities may have smaller sub-micron defects in the PTFE coating from which even degassed water cannot fully remove air [5]. Also, because the top surface of the water is exposed to air, the bulk pool can eventually regain dissolved air due to mass transfer through this top free surface. Natural convection cells will transport the resat- urated cooler water towards the bottom surface where it is heated and thus becomes supersaturated and transfers air to the sub-micron cavities. Once enough air is transported to the surface, the micro-scale cavities can transition to the Cassie-Baxter state and continue the nucleation process. However, here the bubbles take on a different shape since the neighboring cavities are still wetted, the overall SHPo behavior is lost, and the contact angle is notably reduced (compare panel (d) of Fig. 8 and panel (d) of Fig. 13). At the $90{ }^{\circ} \mathrm{C}$ surface temperature set-point the natural convection is the strongest and causes large transport of air from the top free surface to the test surface. As such, large bubbles can eventually form and the majority of the surface can transition to the Cassie-Baxter state, despite the water being initially degassed and starting in a wetted state (see panel (f)).

\subsection{Heat Transfer Results}

In order to compare the the relative thermal performance of the surfaces, the natural convection heat transfer coefficient is calculated as follows

$$
h=\frac{q^{\prime \prime}}{T_{s}-T_{p}}
$$

and averaged over the selected steady-state time period to yield the average heat transfer coefficient $(\bar{h})$ at each set-point. Figure 14 presents the average heat transfer coefficient vs. the average surface temperature $\left(\bar{T}_{s}\right)$ for all the tested surfaces. The data is separated into four panels for clarity in comparing the results.

In panel (a) of Fig. 14 the results for the smooth HPi surface are displayed. A first order estimate of $\bar{h}$ is also computed for the HPi surface from a general free convection correlation for 2D horizontal enclosures [25]

$$
\frac{\bar{h} L}{k}=0.069 \operatorname{Ra} a_{L}^{1 / 3} \operatorname{Pr}^{0.074}
$$




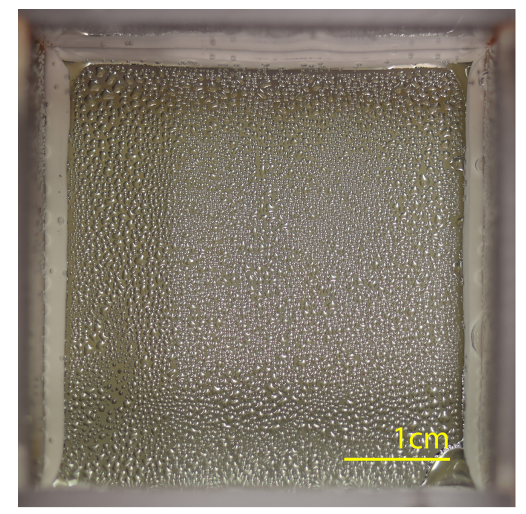

(a) $40^{\circ} \mathrm{C}$

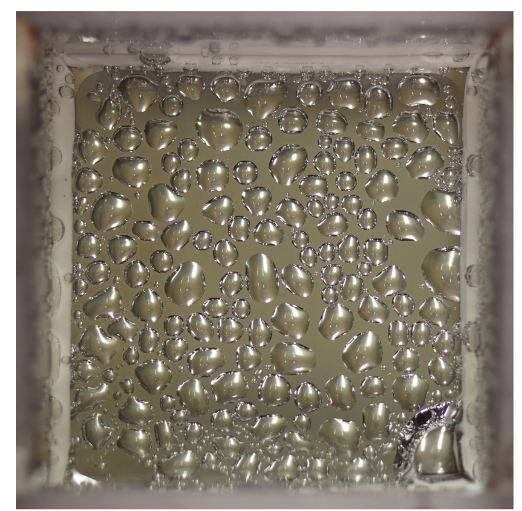

(d) $70^{\circ} \mathrm{C}$

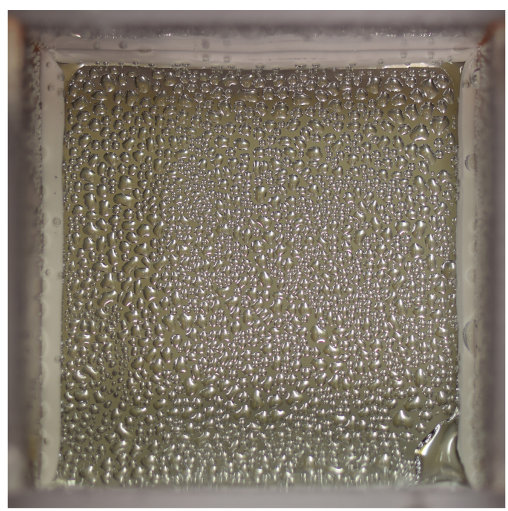

(b) $50^{\circ} \mathrm{C}$

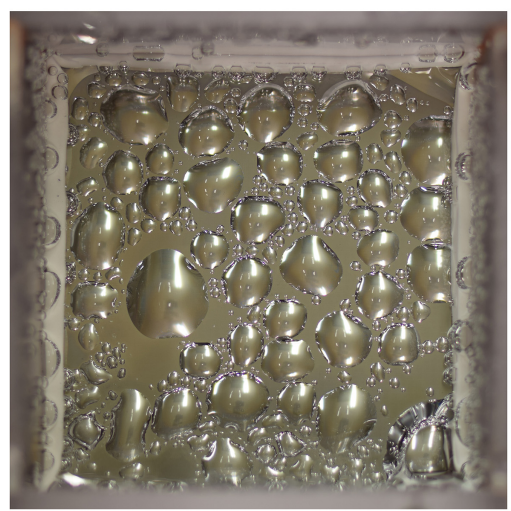

(e) $80^{\circ} \mathrm{C}$

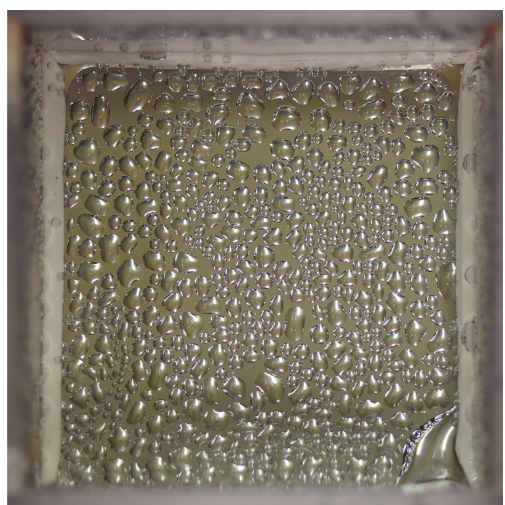

(c) $60{ }^{\circ} \mathrm{C}$

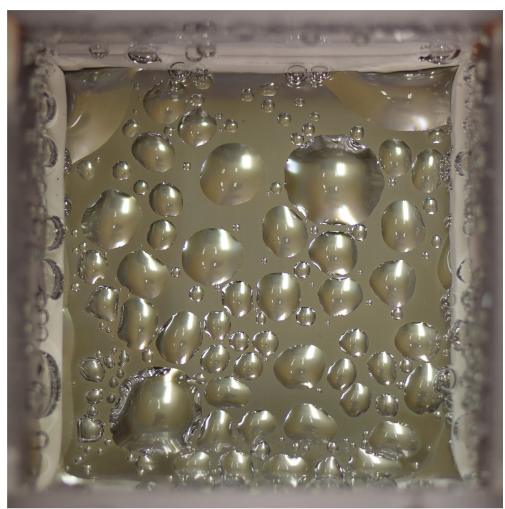

(f) $90^{\circ} \mathrm{C}$

Figure 11: Top-view of nucleation behavior on the SHPo-H surface $\left(w=24.0 \mu \mathrm{m}, F_{c}=0.51\right)$ at the six surface temperature set-points. 


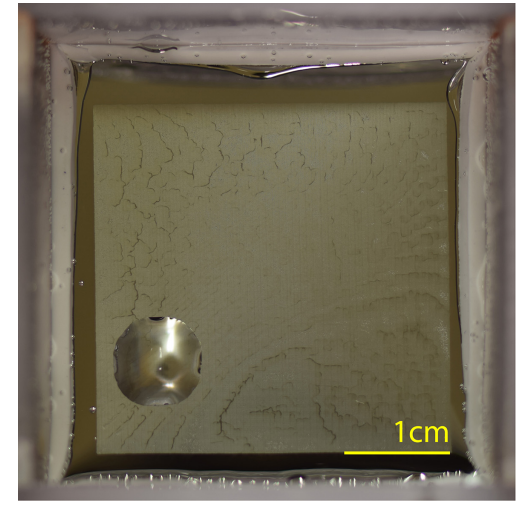

(a) $40^{\circ} \mathrm{C}$

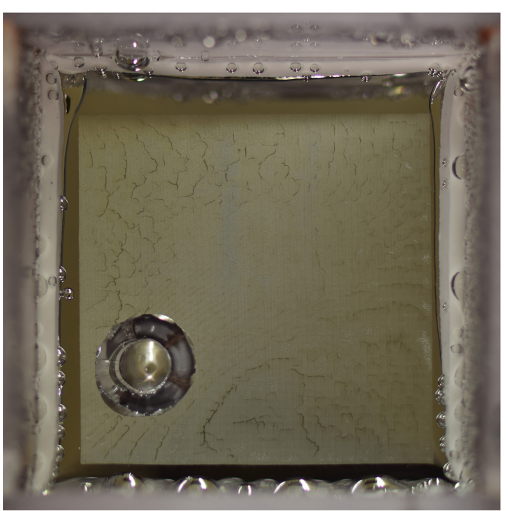

(d) $70^{\circ} \mathrm{C}$

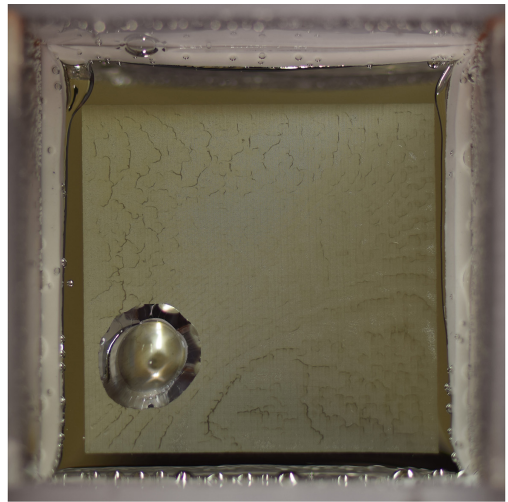

(b) $50^{\circ} \mathrm{C}$

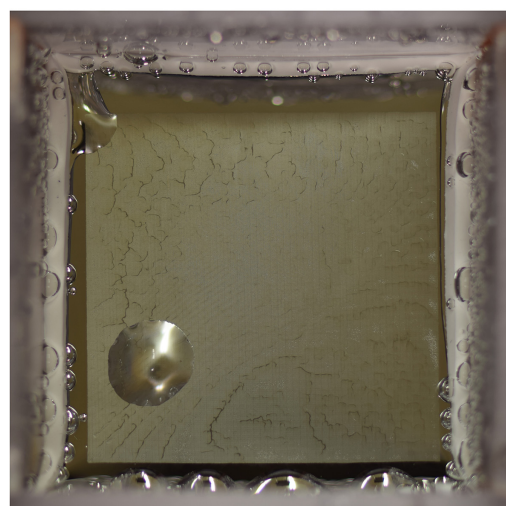

(e) $80^{\circ} \mathrm{C}$

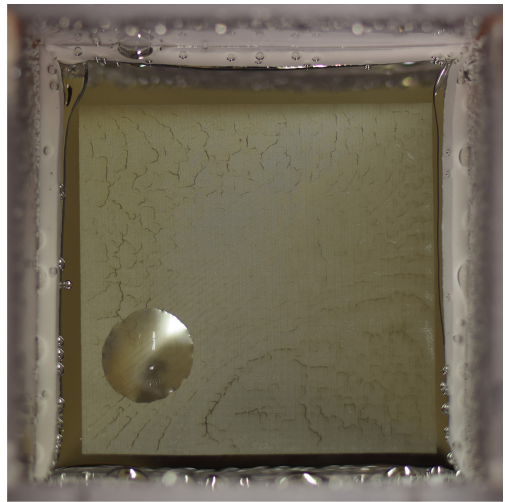

(c) $60^{\circ} \mathrm{C}$

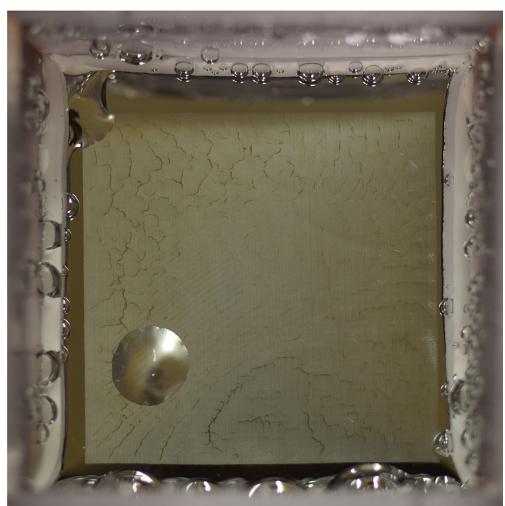

(f) $90^{\circ} \mathrm{C}$

Figure 12: Top-view of nucleation behavior on the SHPo-P* surface $\left(w=23.6 \mu \mathrm{m}, F_{c}=0.60\right)$ at the six surface temperature set-points (the discoloration bands on this surface are due to slight differences in the PTFE coating thickness $(<1 \mu \mathrm{m})$ at the base of the posts and does not affect the nucleation behavior). 


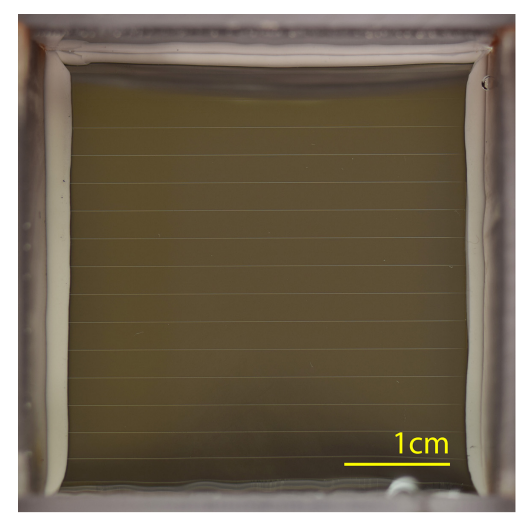

(a) $40^{\circ} \mathrm{C}$

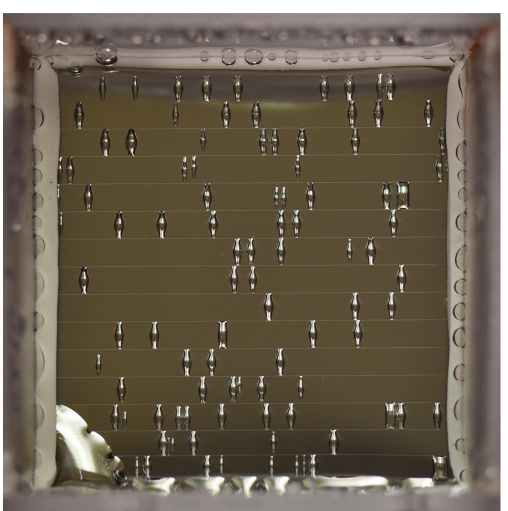

(d) $70{ }^{\circ} \mathrm{C}$

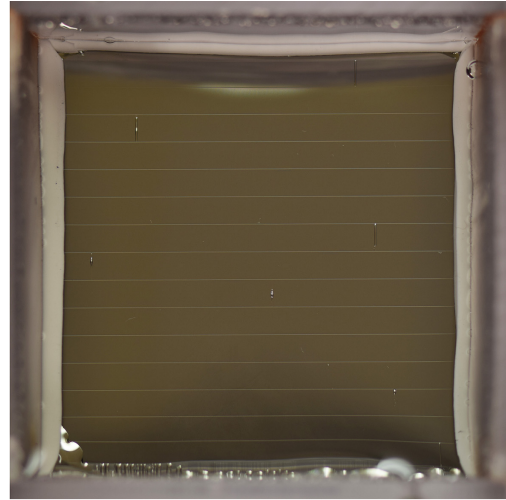

(b) $50^{\circ} \mathrm{C}$

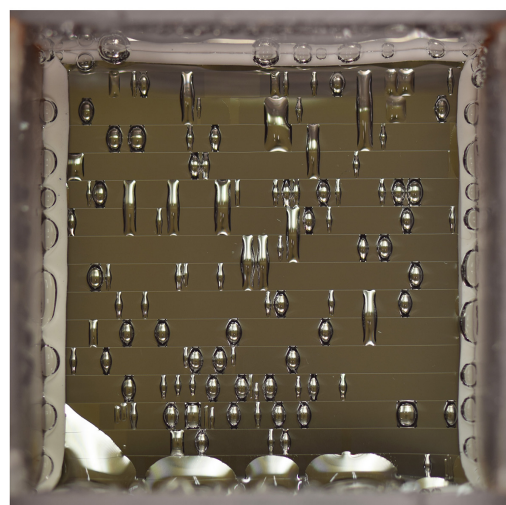

(e) $80^{\circ} \mathrm{C}$

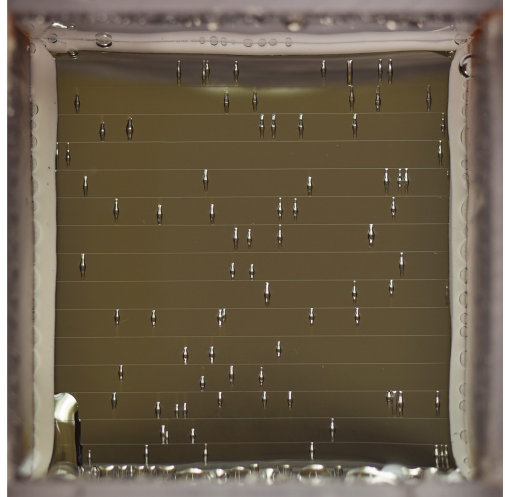

(c) $60^{\circ} \mathrm{C}$

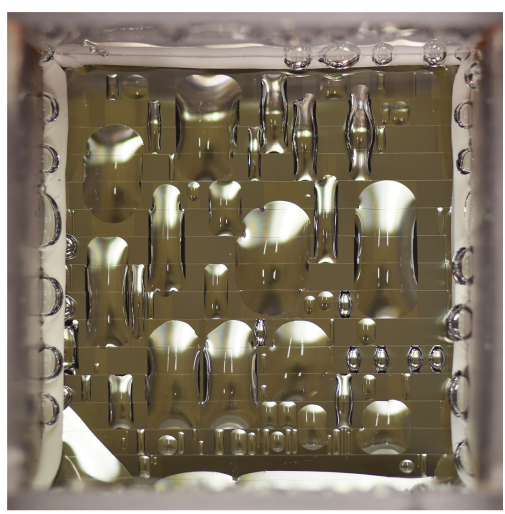

(f) $90^{\circ} \mathrm{C}$

Figure 13: Top-view of nucleation behavior with initially degassed water on the SHPo-R+ surface $\left(w=40.0 \mu \mathrm{m}, F_{c}=0.78\right)$ at the six surface temperature set-points. The predominant rib micro-structure is vertically aligned in the images. 


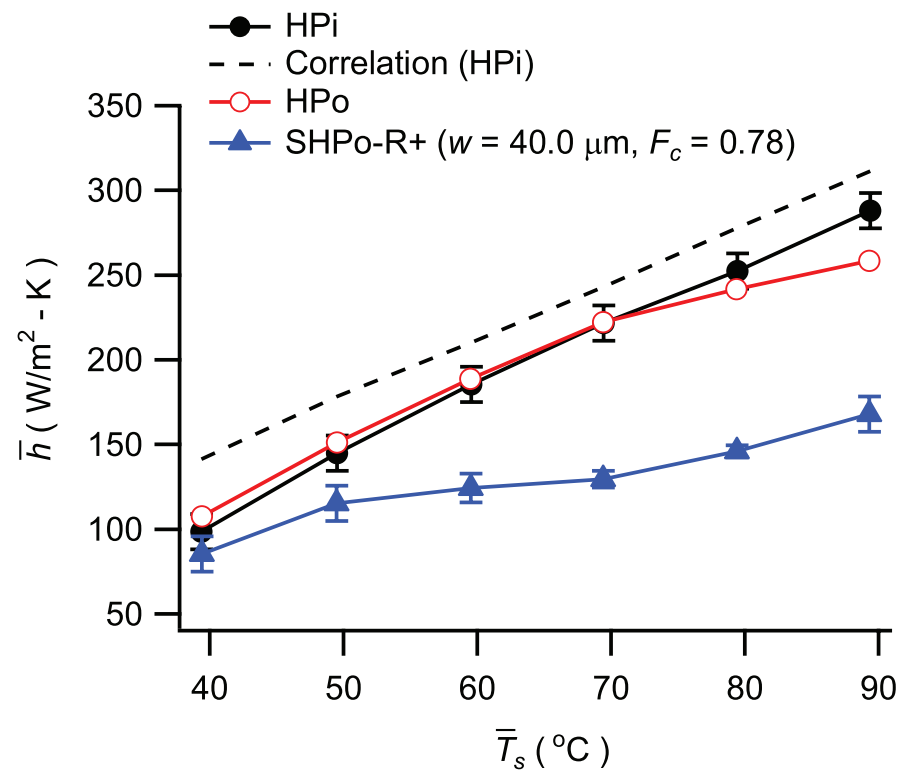

(a)

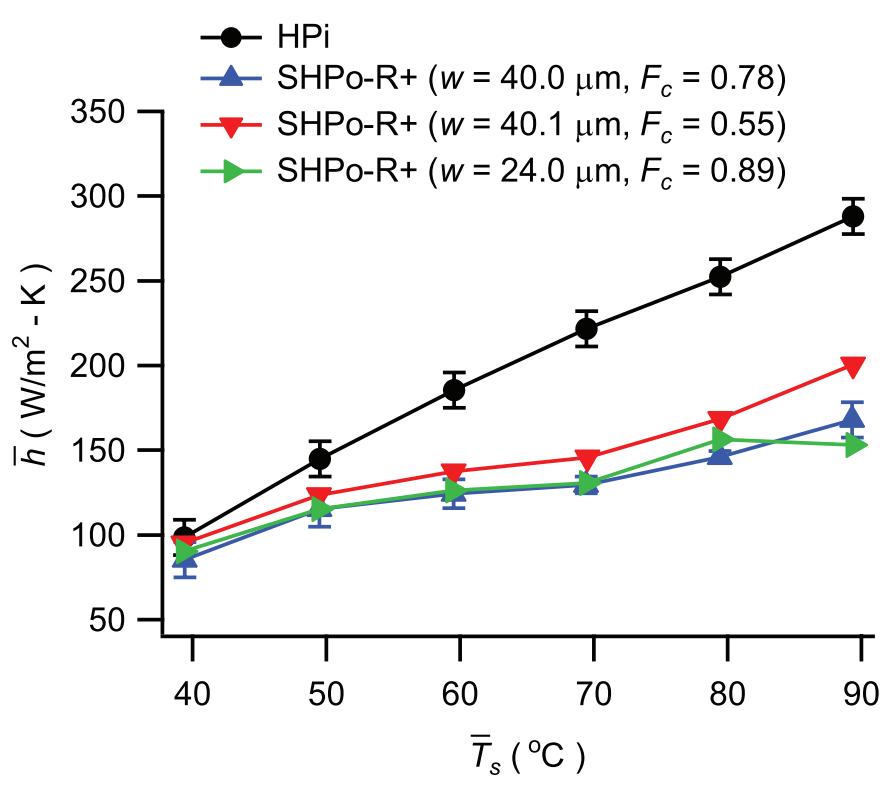

(c)

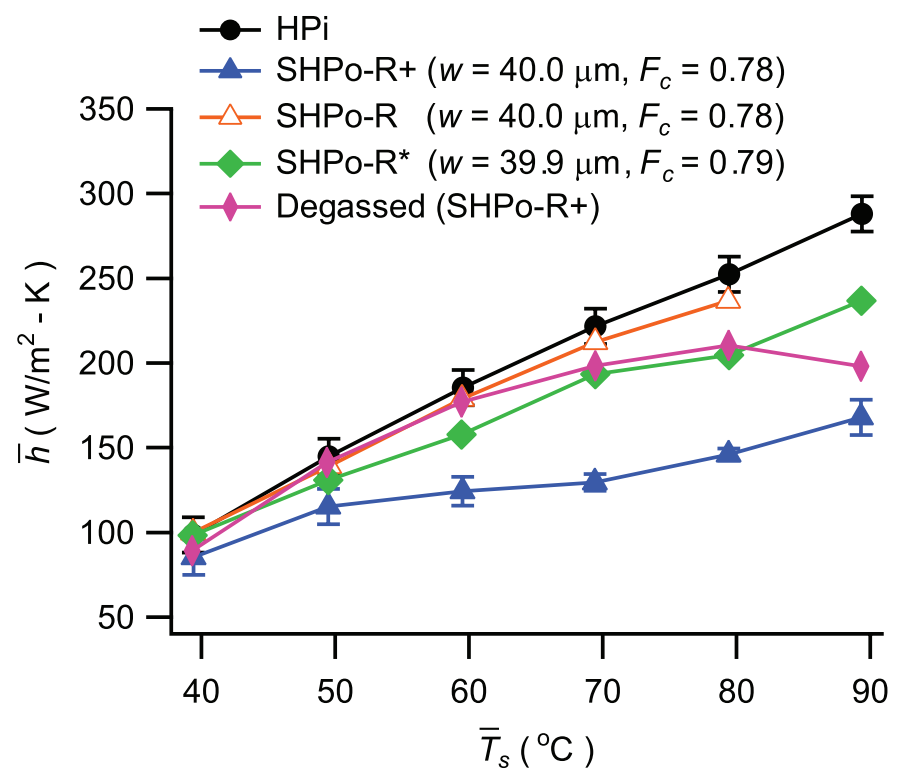

(b)

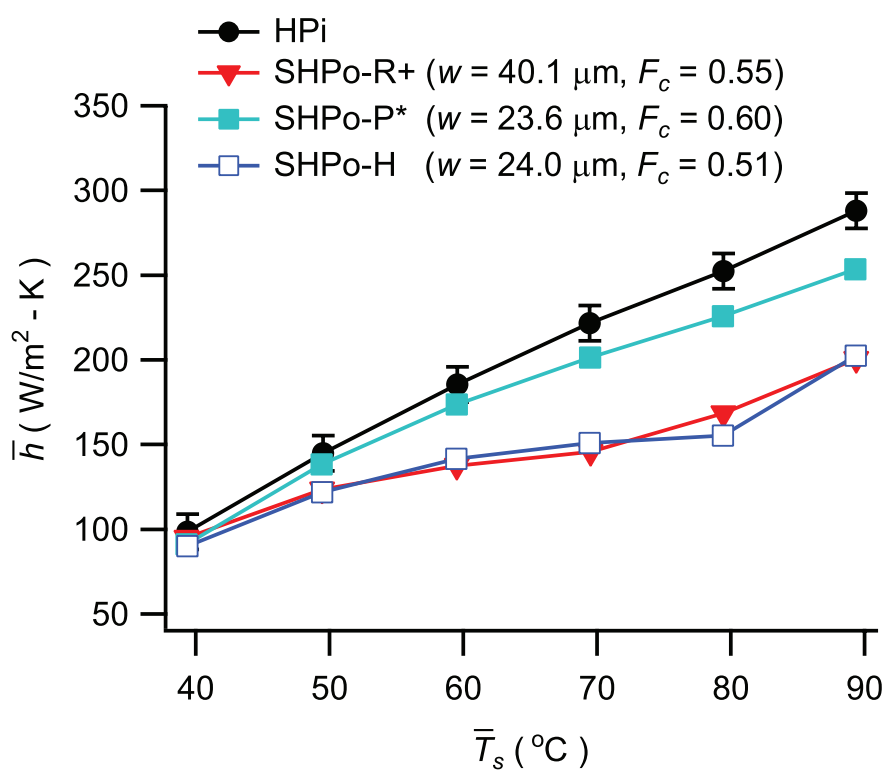

(d)

Figure 14: Average heat transfer coefficient vs. average surface temperature. Panel (a) compares the smooth HPi and HPo surfaces, a basic natural convection correlation [25], and illustrates the uncertainty analysis performed based on the SHPo-R + surface $(w=40.0 \mu m$, $\left.F_{c}=0.78\right)$. Panel $(\mathrm{b})$ compares all the rib/cavity surfaces where $w=40 \mu \mathrm{m}$ and $F_{c}=0.8$ nominally, including the degassed test. Panel (c) compares all the rib/cavity surfaces with sparse perpendicular ribs (i.e. the three SHPo-R+ surfaces). Panel (d) compares the SHPo-R+, SHPo-H, and SHPo-P* surfaces where $F_{c} \approx 0.55$. Results for the HPi surface are repeated in all panels with the worst-case-scenario error bars included for comparison. The lines between markers are included to guide the eye. 
where $k$ is the fluid thermal conductivity, $\operatorname{Pr}$ is the Prandtl number $(\nu / \alpha)$, and $R a_{L}$ is the Rayleigh number

$$
R a_{L}=\frac{g \beta\left(T_{1}-T_{2}\right) L^{3}}{\alpha \nu}
$$

$g$ is the local acceleration due to gravity, $\beta$ is the volumetric thermal expansion coefficient of the fluid, $\alpha$ is the thermal diffusivity of the fluid, $\nu$ is the kinematic viscosity of the fluid, $T_{1}$ and $T_{2}$ are the constant temperatures of the bottom and top surfaces respectively, and $L$ is the separation distance between the surfaces [25]. Note that this correlation is for the classical scenario of two infinite horizontal plates where the bottom plate is heated and the top plate is cooled and both are maintained at fixed temperatures. This is different from the current scenario where the bottom surface is heated and the second temperature measurement occurs in the center of the convective enclosure. Also, the top surface of the present set-up is a free surface rather than a no-slip fixed temperature boundary and the aspect ratio of the $3 \mathrm{D}$ enclosure is such that the sidewalls will affect the results. Despite these limitations, Eq. (4) predicts the linear trend in $\bar{h}$ with decent agreement when the temperature difference $\left(T_{1}-T_{2}\right)$ is replaced by $\left(\bar{T}_{s}-\bar{T}_{p}\right)$ from the HPi test. Note that $L$ cancels out when computing $\bar{h}$ from Eq. (4). $\bar{T}_{p}$ is the temporal average of the pool temperature at a given set-point over the selected steady-state period. All fluid properties are computed at the average of $\bar{T}_{s}$ and $\bar{T}_{p}$.

Three replicate tests are performed on the SHPo-R+ $\left(w=40.0 \mu \mathrm{m}, F_{c}=0.78\right)$ surface to obtain an estimate of the relative uncertainty in $\bar{h}$. This surface is chosen for estimating uncertainty because it has a very large amount of bubbles which leads to the greatest amount of variability and is considered a worst-case-scenario. Between each replicate test the surface is completely removed from the set-up and then reassembled with new thermal paste as described previously to capture variability in the testing procedure due to assembly as well. Presented in panel (a) of Fig. 14 is the mean of the three tests with error bars based on the standard deviation between the replicate tests. The largest standard deviation occurs at the $40{ }^{\circ} \mathrm{C}$ set-point and is $10.4 \mathrm{~W} / \mathrm{m}^{2}-\mathrm{K}$. It is assumed that this worst-case-scenario value is a good indicator for the relative uncertainty in $\bar{h}$ and will be similar for the other surfaces. This worst case value is projected to the HPi surface for visualization. Note that the error bars are only shown on the SHPo-R+ and HPi surfaces for clarity. It can immediately be seen that the SHPo-R + surface drastically decreases in thermal performance, relative to the $\mathrm{HPi}$ and HPo surfaces. This is due to the significant air bubble growth present, where the air bubbles then act as an insulating layer and increase the resistance to heat transfer thus reducing $\bar{h}$.

Panel (a) of Fig. 14 also compares the results from the HPo surface. Note that it performs nominally the same as the HPi surface up until $80^{\circ} \mathrm{C}$. This correlates well with the visualization results which show that air bubbles start to occupy a significant fraction of the HPo surface at the $80{ }^{\circ} \mathrm{C}$ and $90{ }^{\circ} \mathrm{C}$ surface temperatures (see Fig. 5). As noted previously, the air bubbles cause the corresponding reduction in $\bar{h}$ after $80{ }^{\circ} \mathrm{C}$.

In panel (b) of Fig. 14, results for all surfaces with variations of the rib/cavity structure with a nominal pitch of $40 \mu \mathrm{m}$ and cavity fraction 0.8 are shown. Also, the HPi case is shown for reference in all of the panels. The SHPo$\mathrm{R}$ surface has the best thermal performance since it only has the two large bubbles at the edges of the surface ${ }^{2}$ (see Fig. 6). The addition of the box to isolate the cavities from the sides allows for more bubbles to form and decreases the thermal performance of the SHPo-R* ${ }^{*}$ surface (see Fig. 7). Further, addition of sparse transverse ribs (SHPo-R+ surface) allows bubbles to encompass the entire surface and yields the the worst thermal performance (see Fig. 8). Results for the degassed test on the same SHPo-R + surface are also shown. Initially, this surface performs similar to the HPi surface, since it has no bubbles due to the degassed water. However, once nucleation begins, $\bar{h}$ diverges from the HPi test and by $\bar{T}_{s}=90{ }^{\circ} \mathrm{C} \bar{h}$ approaches the value of the $\mathrm{SHPo}-\mathrm{R}+$ test performed with air-saturated water.

Panel (c) of Fig. 14 compares results for all of the different SHPo-R+ surfaces. The SHPo-R+ surface with $w=24.0 \mu \mathrm{m}$ and $F_{c}=0.89$ performs almost the same as the SHPo-R + surface with $w=40.0 \mu \mathrm{m}$ and $F_{c}=0.78$ surface, despite the different rib/cavity pitch values and slightly different cavity fractions. The SHPo-R+ surface with $w=40.1 \mu \mathrm{m}$ and $F_{c}=0.55$ has a marginally better thermal performance since the bubbles are slightly smaller relative to the other two surfaces, as discussed above. Also note, the SHPo-R + surface with $w=40.1 \mu \mathrm{m}$ and $F_{c}=$ 0.55 and the SHPo-R+ surface with $w=24.0 \mu \mathrm{m}$ and $F_{c}=0.89$ have nominally the same cavity width $\left(w_{c}\right)$ yet they perform differently (refer to Table 1). This suggests that the cavity fraction and not the pitch nor the cavity width is a dominant factor affecting $\bar{h}$ for SHPo-R + surfaces, however, additional tests considering the many different combinations of $w, F_{c}, d$, and the sparse rib spacing distance would be required to conclude this definitively. It is evident that all the SHPo-R + surfaces dramatically reduce the thermal performance relative to the HPi surface due to the existence of the growing air bubbles. At $90{ }^{\circ} \mathrm{C}, \bar{h}$ for the SHPo-R + surface with $w=40.0 \mu \mathrm{m}$ and $F_{c}=0.78$ is nominally $40 \%$ less than for the HPi surface.

In panel $(\mathrm{d})$ of Fig. 14 the SHPo-R $+(w=40.1 \mu \mathrm{m}$, $\left.F_{c}=0.55\right)$, SHPo-H $\left(w=24.0 \mu \mathrm{m}, F_{c}=0.51\right)$, and SHPo$\mathrm{P}^{*}\left(w=23.6 \mu \mathrm{m}, F_{c}=0.60\right)$ surfaces, which all have similar cavity fractions, are compared. Note that both of the surfaces with the closed air cavities yield a similar thermal performance (i.e. the SHPo-R+ and SHPo-H surfaces). Since the SHPo-P* surface only has one air bubble which occupied a nearly fixed surface area, it exhibits a

\footnotetext{
${ }^{2}$ Note that this surface was only tested up to $80^{\circ} \mathrm{C}$.
} 
better thermal performance, and $\bar{h}$ is closer to that for the HPi surface. Thus, cavity fraction is not the sole metric of thermal performance; whether or not the air cavities are comprised of open or closed cells also affects the bubble nucleation and consequently the overall thermal performance.

To aid in visualizing the magnitude of the reduction in the overall thermal performance, the heat transfer results are recast as a percent reduction in $\bar{h}$ relative to the HPi test, i.e.

$$
\% \text { reduction }=\left(1-\frac{\bar{h}}{\bar{h}_{\mathrm{HPi}}}\right) \times 100 \%
$$

where $\bar{h}_{\mathrm{HPi}}$ is the convective heat transfer coefficient from the HPi test. Figure 15 presents the percent reduction results vs. surface temperature and is organized into four panels in the same manner as Fig. 14. The uncertainty in the percent heat transfer reduction is determined via a sensitivity analysis of Eq. (6) and using the worst-case error of $10.4 \mathrm{~W} / \mathrm{m}^{2}-\mathrm{K}$ for the uncertainties of $\bar{h}$ and $\bar{h}_{\mathrm{HPi}}$. The uncertainty is the same for each series of tests but is illustrated graphically with error bars on only one series per panel for clarity. As noted previously, the SHPo-R+ surfaces with larger cavity fractions exhibit the greatest reduction in $\bar{h}$ due to their propensity to exhibit large bubble growth. In general, the percent reduction trends exhibited in Fig. 15 agree well with the qualitative visualization images in regards to bubble size and coverage (i.e. the surfaces with the most bubbles exhibit the greatest reduction in heat transfer coefficient relative to the practically bubble free HPi surface).

For all SHPo test cases performed, the thermal performance is reduced in comparison to a smooth HPi surface ${ }^{3}$. SHPo surfaces are designed to have air trapped in the cavities, however, the magnitude of heat transfer reduction observed here is not solely due to the air (which has a thermal conductivity much less than that of the silicon substrate) confined in the micro-scale cavities. Large air bubbles are able to nucleate due to the mass transfer of dissolved air in the bulk liquid to the air cavities on the surface. This occurs because water is a temperature dependent solvent of the main gases that compose air (i.e. Nitrogen and Oxygen). Even when the water was initially degassed, the SHPo-R + surface was able to eventually exhibit large nucleation bubbles due to air transport at the free surface and sub-micron defects on the surface that never fully wetted. Perhaps nucleation could be avoided if the surface was completely degassed and the bulk liquid was not exposed to air, however, this would lead to fully wetted cavities and defeat the purpose of using a SHPO surface. Also, if the test surfaces were cooled instead of heated, it is expected that the water would become undersaturated and absorb air from the cavities, leading to a

\footnotetext{
${ }^{3}$ At $40{ }^{\circ} \mathrm{C}$ the SHPo-R surface has a slightly higher $\bar{h}$ value than the HPi surface, but it is well within the estimated uncertainty.
}

wetted state. Thus, this work strongly suggests that heat and mass transfer cannot be separated on SHPo surfaces when water is the the working liquid. Additionally, the micro-structure is critical in determining the quantity and structure of the bubbles that are able to nucleate on the surface. Specifically, if the air cavities are fully connected in a network, only a single bubble forms in order to minimize surface energy, however, if the cavities are isolated from one another, many bubbles can form.

\subsubsection{Consideration of the SHPo surface geometry effects}

For completeness, the temperature drop associated with the structure of the SHPo surface is discussed here. Previous works have characterized the heat transfer reduction due to SHPo surface structures via thermal spreading resistance type calculations $[16,19]$. These works present the results in terms of an apparent temperature jump length $[16]$

$$
\Delta \hat{T}=\hat{T}_{s}-\hat{T}_{c}=-\left.b_{t} \frac{d \hat{T}}{d n}\right|_{c}
$$

where $\hat{T}_{s}$ is the temperature of the liquid/solid interface, $\hat{T}_{c}$ is the average temperature of the composite liquid/solid and air/liquid interface, $b_{t}$ is the temperature jump length, and $d \hat{T} /\left.d n\right|_{c}$ is the average temperature gradient normal to the composite interface. A complete description of the temperature jump length can be found in several references and is not discussed in depth here [14-17, 19].

For our purposes, it can be used to estimate the temperature drop associated with the geometry of the SHPo surface structures. Utilizing Fourier's law we can estimate the temperature drop in terms of the jump length as $\Delta \hat{T}=\bar{q}^{\prime \prime} b_{t} / k$. For the SHPo-R + surface with $w=40.0$ $\mu \mathrm{m}$ and $F_{c}=0.78$, the temperature jump length is computed to be $6.9 \mu \mathrm{m}$ using an analytical expression from the work of Enright et al. [16] for a constant surface temperature condition. For the extreme case of $90{ }^{\circ} \mathrm{C}$, where the average heat flux is about $550 \mathrm{~W} / \mathrm{m}^{2}-\mathrm{K}$, the computed temperature jump length corresponds to a temperature drop of only about $5.6 \times 10^{-3}{ }^{\circ} \mathrm{C}$. This is more than two orders of magnitude lower than the average temperature difference used to compute the heat transfer coefficient for this case and is well below the differential resolution of the thermocouples used. Thus, the large reduction in heat transfer seen here is not influenced by the underlying micro-structure geometry alone, rather the complex resultant nucleation behavior and the macroscopic air layer formed that has been discussed.

\section{Conclusions}

This work has experimentally explored the nucleation of air bubbles on SHPo surfaces due to mass transport at sub-critical temperatures. Structured SHPo surfaces provide air cavities for nucleation to occur. More bubbles are observed on the superhydrophobic surfaces with the closed 


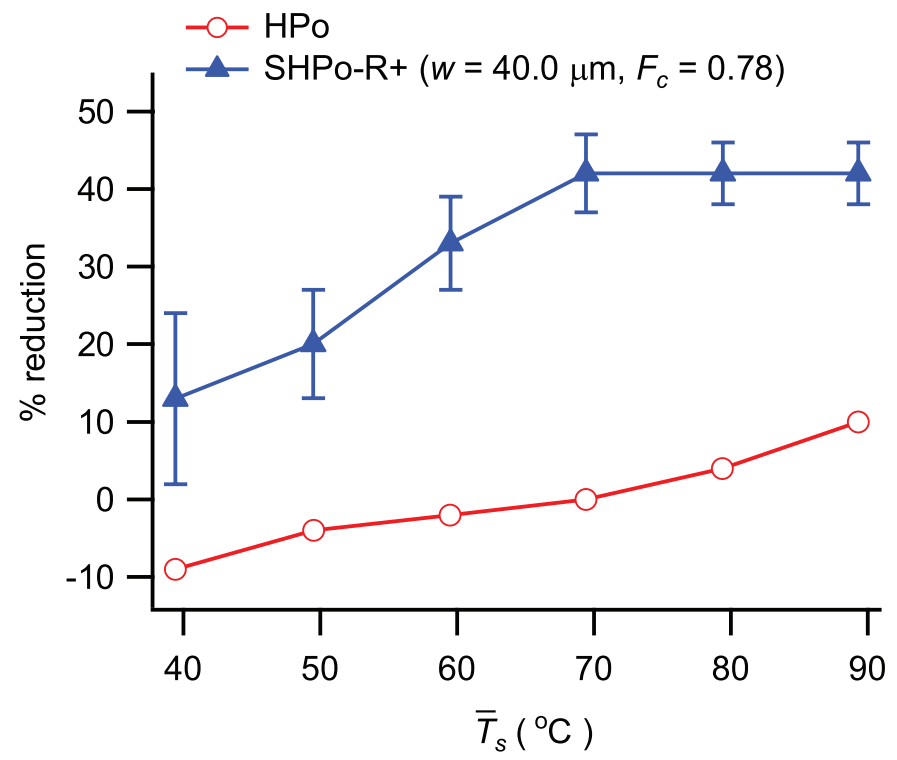

(a)

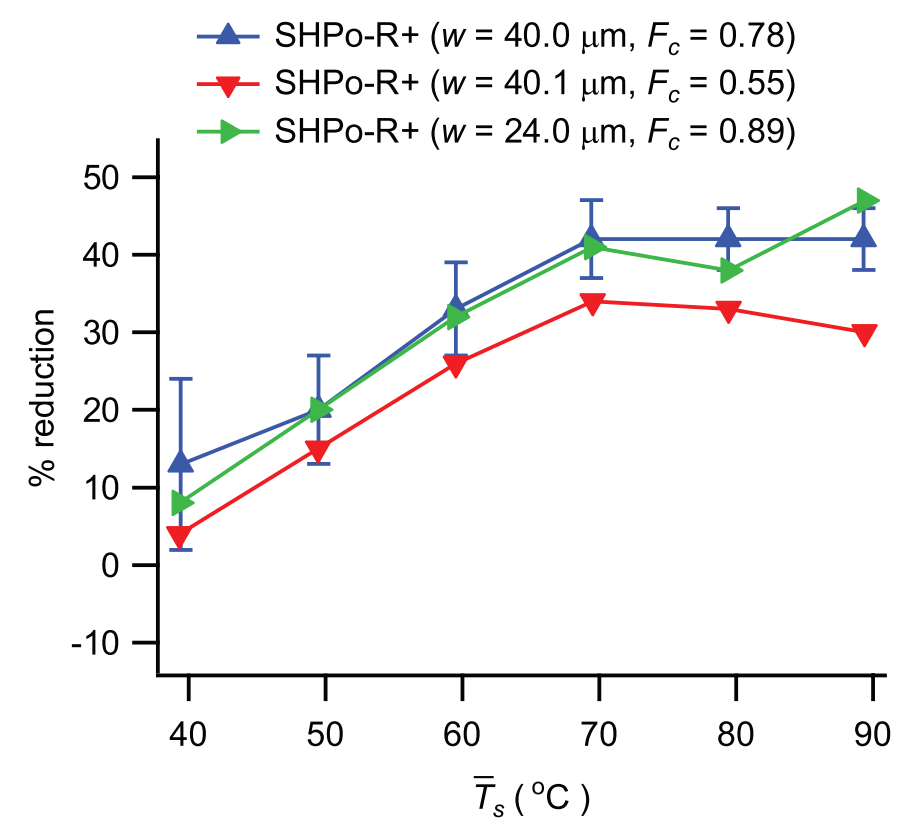

(c)

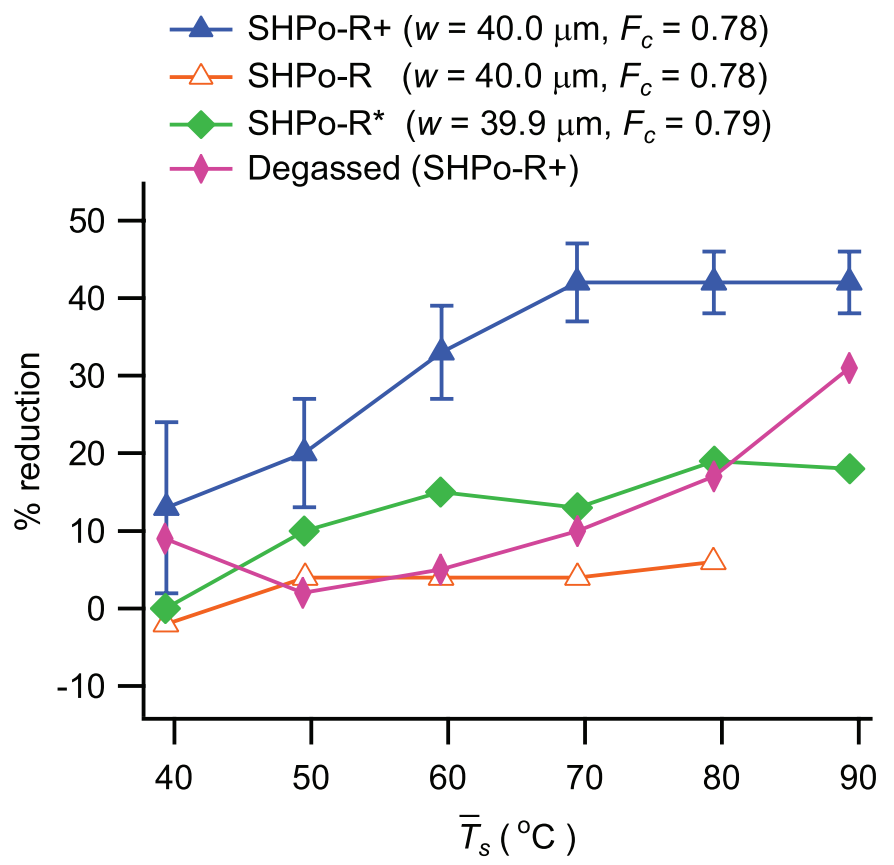

(b)

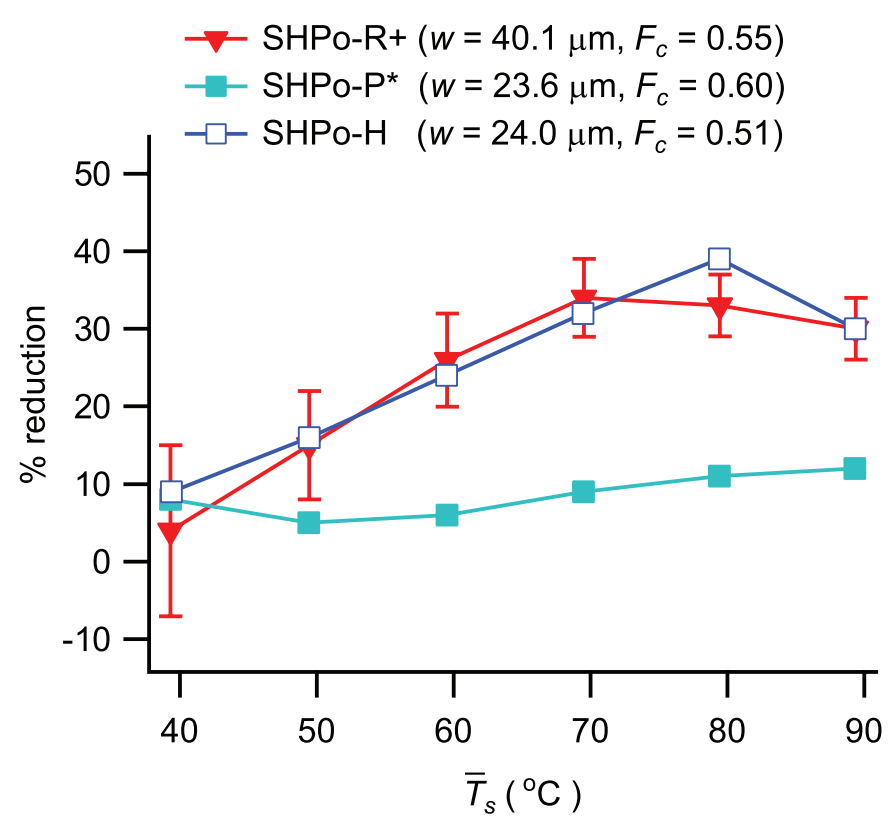

(d)

Figure 15: Percent reduction in the average heat transfer coefficient relative to the HPi test vs. average surface temperature. Panel (a) compares the smooth HPo and SHPo-R $+\left(w=40.0 \mu \mathrm{m}, F_{c}=0.78\right)$ surfaces. Panel (b) compares all the rib/cavity surfaces where $w=40 \mu \mathrm{m}$ and $F_{c}=0.8$ nominally, including the degassed test. Panel (c) compares all the rib/cavity surfaces with sparse perpendicular ribs (i.e. the three SHPo-R+ surfaces). Panel (d) compares the SHPo-R+, SHPo-H, and SHPo-P* surfaces where $F_{c} \approx 0.55$. Uncertainty in the percent reduction based on the worst-case-scenario error is the same for all series but is only depicted only on one series per panel for clarity. The lines between markers are included to guide the eye. 
off cavities and when air-saturated water is used. As the surface temperature increases, more air effervesces onto the surface due to an increased level of supersaturation and convection such that heat and mass transfer cannot be treated independently. The nucleation leads to large air bubble formations that reduce the overall convection coefficient when compared to the smooth surfaces. The bubbles form in a manner that is dependent on the surface structure. Cavity fraction and the underlying microstructure are found to be the dominant factors affecting the bubble nucleation behavior and the thermal performance of the surfaces studied. The SHPo surfaces patterned with ribs and sparse perpendicular ridges (SHPo$\mathrm{R}+$ ) and those patterned with circular holes (SHPo-H) exhibit the greatest amounts of nucleation and therefore the largest reduction to heat transfer relative to a smooth HPi surface. While those patterned with just ribs (SHPo$\left.\mathrm{R}^{*}\right)$ and those patterned with posts $\left(\mathrm{SHPo}^{*}\right)$ cause a less dramatic reduction to heat transfer.

\section{Acknowledgments}

This research was supported by the National Science Foundation (NSF) (Grant No. CBET-1235881) and a fellowship from the Utah NASA Space Grant Consortium (NASA Grant NNX15A124H). A special thanks to Matthew Searle for the design and fabrication of the experimental set-up.

\section{References}

[1] A. B. D. Cassie, S. Baxter, Wettability of porous surfaces, Trans. Faraday Soc. 40 (1944) 546-551.

[2] P.-G. de Gennes, F. Brochard-Wyart, D. Quéré, Capillarity and Wetting Phenomena: Drops, Bubbles, Pearls, Waves, SpringerVerlag, 2004.

[3] J. Kadoko, G. Karamanis, T. Kirk, M. Hodes, One-dimensional analysis of gas diffusion-induced Cassie to Wenzel state transition, Journal of Heat Transfer 139 (12) (2017) 122006-12200610.

[4] R. Sander, Compilation of Henry's law constants (version 4.0) for water as solvent, Atmospheric Chemistry and Physics 15 (8) (2015) 4399-4981.

[5] N. A. Patankar, Thermodynamics of trapping gasses for underwater superhydrophobicity, Langmuir 32 (27) (2016) 7023-7028.

[6] M. Xu, G. Sun, C.-J. Kim, Infinite lifetime of underwater superhydrophobic states, Phys. Rev. Lett. 113 (13) (2014) 136103.

[7] B. Emami, A. A. Hemeda, M. M. Amrei, A. Luzar, M. G. el Hak, H. V. Tafreshi, Predicting the longevity of submerged superhydrophobic surfaces with parallel grooves, Physics of Fluids 25 (6) (2013) 062108-1-17.

[8] M. R. Flynn, J. W. M. Bush, Underwater breathing: The mechanics of plastron respiration, Journal of Fluid Mechanics 608 (2008) 275-296.

[9] I. U. Vakarelski, D. Y. C. Chan, J. O. Marston, S. T. Thoroddsen, Dynamic air layer on textured superhydrophobic surfaces, Langmuir 29 (2013) 11074-11081.

[10] X. Wang, S. Zhao, H. Wang, T. Pan, Bubble formation on superhydrophobic-micropatterned copper surfaces, Applied Thermal Engineering 35 (2012) 112 - 119.

[11] A. Cowley, D. Maynes, J. Crockett, B. D. Iverson, Bubble nucleation in superhydrophobic microchannels due to subcritical heating, International Journal of Heat and Mass Transfer 121 (2018) $196-206$.
[12] P. Lv, Y. Xiang, Y. Xue, H. Lin, H. Duan, Morphological bubble evolution induced by air diffusion on submerged hydrophobic structures, Physics of Fluids 29 (3) (2017) 032001.

[13] D. Maynes, B. W. Webb, J. Davies, Thermal transport in a microchannel exhibiting ultrahydrophobic micro-ribs maintained at constant temperature, Journal of Heat Transfer 130 (2008) 022402-1-8.

[14] D. Maynes, J. Crockett, Apparent temperature jump and thermal transport in channels with streamwise rib and cavity featured superhydrophobic walls at constant heat flux, Journal of Heat Transfer 136 (2014) 011701-1-10.

[15] D. Maynes, B. W. Webb, J. Crockett, V. Solovjov, Analysis of laminar slip-flow thermal transport in microchannels with transverse rib and cavity structured superhydrophobic walls at constant heat flux, Journal of Heat Transfer 135 (2013) 021701$1-10$.

[16] R. Enright, M. Hodes, T. Salamon, Y. Muzychka, Isoflux Nusselt number and slip length formulae for superhydrophobic microchannels, Journal of Heat Transfer 136 (2014) 012402-1-9.

[17] A. Cowley, D. Maynes, J. Crockett, Effective temperature jump length and influence of axial conduction for thermal transport in superhydrophobic channels, International Journal of Heat and Mass Transfer 79 (2014) 573-583.

[18] A. Cowley, D. Maynes, J. Crockett, Inertial effects on thermal transport in superhydrophobic microchannels, International Journal of Heat and Mass Transfer 101 (2016) $121-132$.

[19] C.-O. Ng, C. Y. Wang, Temperature jump coefficient for superhydrophobic surfaces, Journal of Heat Transfer 136 (2014) 064501-1-6.

[20] L. S. Lam, M. Hodes, R. Enright, Analysis of Galinstan-based microgap cooling enhancement using structured surfaces, Journal of Heat Transfer 137 (2015) 091003-1-10.

[21] D. Moreira, P. R. Bandaru, Thermal transport in laminar flow over superhydrophobic surfaces, utilizing an effective medium approach, Physics of Fluids 27 (2015) 052001-1-14.

[22] K.-Y. Law, Definitions for hydrophilicity, hydrophobicity, and superhydrophobicity: Getting the basics right, The Journal of Physical Chemistry Letters 5 (4) (2014) 686-688.

[23] S. F. Jones, G. M. Evans, K. P. Galvin, Bubble nucleation from gas cavities - a review, Advances in Colloid and Interface Science 80 (1999) 27-50.

[24] S. H. Huynh, A. A. A. Zahidi, M. Muradoglu, B. H.-P. Cheong, T. W. Ng, Plastron-mediated growth of captive bubbles on superhydrophobic surfaces, Langmuir 31 (24) (2015) 6695-6703.

[25] F. P. Incropera, D. P. DeWitt, T. L. Bergman, A. S. Lavine, Fundamentals of heat and mass transfer., 6th Edition, John Wiley and Sons, Inc., 2007. 